\title{
Spectral karyotyping of human, mouse, rat and ape chromosomes - applications for genetic diagnostics and research
}

\author{
E. Schrock ${ }^{\mathrm{a}}$ P. Zschieschang ${ }^{\mathrm{a}}$ P. O'Brien ${ }^{\mathrm{b}}$ A. Helmrich ${ }^{\mathrm{c}}$ T. Hardt ${ }^{\mathrm{a}}$ \\ A. Matthaei ${ }^{a} \quad$ K. Stout-Weider ${ }^{d}$ \\ ${ }^{a}$ Institut für Klinische Genetik, Medizinische Fakultät Carl Gustav Carus, Technische Universität Dresden, \\ Dresden (Germany); \\ ${ }^{\mathrm{b}}$ Department of Clinical Veterinary Medicine, Centre for Veterinary Science, Veterinary Cytogenetics Group, \\ Madingley Road, Cambridge (UK); \\ 'Institut de Génétique et de Biologie Moléculaire et Cellulaire, CU de Strasbourg, Illkirch (France); \\ ${ }^{\mathrm{d}}$ Institut für Medizinische Genetik, Charité - Universitätsmedizin Berlin, Campus Virchow-Klinikum, \\ Berlin (Germany)
}

Manuscript received 8 May 2006; accepted in revised form for publication by T. Liehr, 19 May 2006.

\begin{abstract}
Spectral karyotyping (SKY) is a widely used methodology to identify genetic aberrations. Multicolor fluorescence in situ hybridization using chromosome painting probes in individual colors for all metaphase chromosomes at once is combined with a unique spectral measurement and analysis system to automatically classify normal and aberrant chromosomes. Based on countless studies and investigations in many laboratories worldwide, numerous new chromosome translocations and other aberrations have been identified in clinical and tumor cytogenetics. Thus, gene identification studies have been facilitated resulting in the dissection of tumor development and progression. For example, different translocation partners of the TEL/ETV6 transcription factor that is specially required for hemato-
\end{abstract}

poiesis within the bone marrow were identified. Also, the correct classification of complex karyotypes of solid tumors supports the prognostication of cancer patients. Important accomplishments for patients with genetic diseases, leukemias and lymphomas, mesenchymal tumors and solid cancers are summarized and exemplified. Furthermore, studies of disease mechanisms such as centromeric DNA breakage, DNA double strand break repair, telomere shortening and radiation-induced neoplastic transformation have been accompanied by SKY analyses. Besides the hybridization of human chromosomes, mouse karyotyping has also contributed to the comprehensive characterization of mouse models of human disease and for gene therapy studies.
Spectral karyotyping was published in 1996 (Schrock et al., 1996) and is a well established fluorescence in situ hybridisation (FISH) technique that refers to the molecular cytogenetic analysis of metaphase preparations by means

\footnotetext{
This work was supported by the German Federal Ministry of Education and Research, BMBF, BioFuture grant 0311875 (ES).

Request reprints from Evelin Schrock, MD, Professor

Institut für Klinische Genetik, Medizinische Fakultät Carl Gustav Carus Technische Universität Dresden, Fetscherstraße 74 DE-01307 Dresden (Germany) telephone: +49-351-458 5136; fax: +49-351-458 6337 e-mail: evelin.schrock@tu-dresden.de
}

of spectral microscopy. Extensive theoretical considerations provided the basis for the success of the spectral karyotyping (SKY) technology in daily practice of routine karyotyping and in research (Schrock et al., 1996; Garini et al., 1999). The probes are labeled by degenerate oligonucleotide primed PCR using three fluorochromes and two haptens. Each probe is differentially labeled with one, two, three or four fluorescent dyes, resulting in a unique spectral signature for every chromosome. After in situ hybridisation and immunodetection, a spectral image is acquired using a conventional fluorescence light microscope equipped with a custom-designed triple-bandpass filter and the SpectraCube ${ }^{\circledR}$, which is able to retrieve spectral

$\begin{array}{lll}\text { KARGER } & \begin{array}{l}\text { Fax }+41613061234 \\ \text { E-Mail karger@karger.ch } \\ \text { www.karger.com }\end{array} & \text { ๑ 2006 S. Karger AG, Basel } \\ 1424-8581 / 06 / 1144-0199 \$ 23.50 / 0\end{array}$


information for every pixel in a digital CCD image. The 24-colour display and chromosome classification are based on the unique emission spectra of the chromosomes. Together with chromosome banding information from an inverted DAPI or a G-banded metaphase, a comprehensive overview and detailed information of chromosomal aberrations is obtained using the automated Software SKYView $^{\circledR}$ and HiSKY ${ }^{\circledR}$ (Applied Spectral Imaging, Inc., Migdal Ha'Emek, Israel). Results for patient diagnostics and prognostication should always be confirmed using locus-specific probes.

To catalog data on chromosomal aberrations in cancer derived from emerging molecular cytogenetic techniques and to integrate these data with genome maps, Knutsen et al. (2005) have established two resources, the NCI and NCBI SKY/M-FISH and CGH Database and the Cancer Chromosomes database. These datasets can be searched seamlessly by use of the Entrez search and retrieval system.

Reviews of the advances by using the SKY technology have been published periodically (Popescu, 2000; Schrock and Padilla-Nash, 2000; Bayani and Squire, 2001, 2002; Xu and Chen, 2003).

SKY has also been applied in conjunction with several other methods. Identifying genes that flank chromosomal reconfigurations is an important task in cancer cytogenetics. Tonon et al. (2000) developed a novel approach to identify gross chromosomal aberrations as well as to detect the involvement of specific loci in these rearrangements in a single step. This method will be particularly useful for the analysis of complex karyotypes and for testing hypotheses arising from cancer gene expression studies (Tonon et al., 2000). Technically also supportive of determining chromosomal aberrations is the combination of SKY analysis, microdissection of distinct aberrant chromosome and reverse painting (Weimer et al., 2001). Combined protocols involving SKY, FISH and immunostaining allow for the tracking of key genes or targeted chromosome regions while monitoring changes throughout the whole genome. This approach facilitates the simultaneous monitoring of protein complexes and DNA loci within the genome (Ye et al., 2001).

The resolution limit of SKY to detect interchromosomal changes was originally determined to be in the range of 1$2 \mathrm{Mb}$ when analyzing metaphases obtained from lymphocytes or amniocytes (Schrock et al., 1996). This finding was independently confirmed (Fan et al., 2001). Limitations of chromosome classification by SKY and M-FISH were determined by Lee et al. (2001). Depending on the length of the chromosomes, false insertions may be interpreted at the interface of translocated segments. Also, small insertions may be misinterpreted or completely missed. Difficult to identify are coamplifications involving material from nonhomologous chromosomes.

Nevertheless, the power of the technology in experienced hands cannot be overrated. The following chapters will illustrate the different applications and demonstrate the usefulness of the SKY analysis.

\section{Applications of chromosome analysis using SKY in clinical genetics}

The identification of chromosome aberrations or the description of a normal karyotype is important for patients afflicted with genetic diseases. A correct diagnosis is very helpful for the further concerted actions of the patients, the family members, the medical doctors and genetic counsellors. The SKY technology has widely been used for prenatal and postnatal diagnostics, in particular for delineating balanced and unbalanced translocations and for determining the chromosomal origin of marker chromosomes. Genotype-phenotype correlations of patients who either share similar phenotypes or whose chromosome aberrations involve overlapping DNA sequences support the strategies of disease gene identification. The following examples of preand postnatal cases illustrate the power of the SKY methodology contributing to a precise diagnosis in patients.

A hidden Down syndrome was suspected because of abnormal ultrasound findings in two fetuses at 18 and 30 weeks of gestation. In the first case, the origin of additional material on chromosome 1pter was determined by SKY as being derived from chromosome 21 and the karyotype was designated as $46, \mathrm{XY}, \operatorname{der}(1) \mathrm{t}(1 ; 21)(\mathrm{p} 36.3 ; \mathrm{q} 22.1)$.ish der(1)(WCP21+, LSI21+, 1pTEL-, 21q TEL+) de novo (Hsieh et al., 2004). In the second case, an unbalanced situation was revealed as $46, \mathrm{XY}, \mathrm{der}(21) \mathrm{t}(20 ; 21)$ (q13.2;q22.13 or 22.2)mat, with the mother and maternal grandmother being balanced translocation carriers (Leppig et al., 2000). Autism and developmental delay in a patient were found to be related to a de novo translocation $\mathrm{t}(2 ; 8)(\mathrm{q} 32 ; \mathrm{q} 21.2)$ accompanied by a cryptic deletion at the breakpoint on chromosome 2 (Borg et al., 2002). An infant born with total anomalous pulmonary venous return (TAPVR) showed an extra ring chromosome resulting from a duplication involving the short arm of chromosome 12 (Harris et al., 2004). A very rare de novo Y-autosome translocation consisting of chromosomal regions on chromosomes 5 and $\mathrm{Y}$ was found in association with a partial duplication of Yq in a male newborn patient with Cri-du-chat syndrome (karyotype 46, XY.ish der(5)t(Y; 5)(q11.2;p15.3)(SKY+,Xq/YqTEL+,5pTEL-)) (Chen et al., 2005). Other studies were performed with comparable results (Schrock et al., 1997; Phelan et al., 1998; Peschka et al., 1999; Heng et al., 2003). Surprisingly, a complex chromosomal rearrangement consisting of 16 fragments was reported in a boy with moderate mental retardation and very short stature. The karyotypes of his parents and his brother were normal (Houge et al., 2003).

A combination of subtelomeric FISH and SKY analysis was performed in order to study 50 children with idiopathic MR or developmental delay and normal GTG-banded karyotypes (Clarkson et al., 2002). Three rearrangements were detected by subtelomeric FISH: a derivative chromosome 5 from a maternal $\mathrm{t}(5 ; 21)$, a recombinant chromosome 11 from a paternal pericentric inversion, and a partial deletion on the long arm of chromosome 2 that was present in the mother as well. The derivative chromosome 5 was also detected by SKY, whereas the other two aberrations were too 
small to be seen. In addition, SKY analysis revealed a lowlevel mosaicism for trisomy 9 in one patient. Unbalanced subtelomeric translocations were also confirmed by SKY subsequent to subtelomere FISH in three out of four patients (Anderlid et al., 2002).

Extra structurally abnormal chromosomes (ESACs) and cryptic rearrangements are often associated with mental retardation and phenotypic abnormalities. SKY analysis permitted the classification of marker chromosomes and chromosome rearrangements and the results were confirmed by using locus/gene-specific probes with FISH analysis (Haddad et al., 1998; Huang et al., 1998; Ning et al., 1999; Yaron et al., 2003; Guanciali-Franchi et al., 2004; Tabet et al., 2004). However, in two cases of small bisatellited chromosomes, SKY was noncontributory (Yaron et al., 2003). Nevertheless, often one can gain suggestions from which chromosomes ESACs might be derived by using the SKY analysis. Thus, a small series of subsequent FISH experiments will elucidate the exact chromosomal origin.

Mosaic karyotypes with 1-6 supernumerary marker chromosomes were identified in a 7-month-old boy with developmental delay and congenital abnormalities and a 58year-old man with mental retardation, impaired speech, and dysmorphic features. The majority of the markers appeared like rings and were rather small showing only minute amounts of euchromatin. SKY analysis followed by chromosome painting was performed to determine the origin of the marker chromosomes. Based on their own observations and a review of the literature the authors suggested that the nature and extent of the euchromatin content of the multiple markers appeared to determine the phenotype of the patients (Reddy et al., 2003).

Fibroblast cultures from two patients with Werner syndrome (WS) were analyzed by SKY detecting multiple, pseudodiploid clones, mostly marked by random balanced reciprocal translocations. The study confirmed the existence of variegated translocation mosaicism as the cytogenetic hallmark of WS fibroblast cultures. It was suggested that tetraploidization in combination with certain chromosome rearrangements and selective chromosome dosage may overcome the severely limited in vitro lifespan of WS fibroblasts (Melcher et al., 2000).

Spontaneous abortions may be caused by unbalanced translocations as a result of a balanced situation in one of the parents. Prenatal diagnostics using SKY analysis allowed for the identification of parental complex translocation carriers and of chromosome rearrangements in the fetuses (Tanemura et al., 2001). For instance, the karyotype $46, \mathrm{XX}, \mathrm{t}(8 ; 11 ; 12)(8 \mathrm{qter} \rightarrow 8 \mathrm{p} 10:: 12 \mathrm{p} 10 \rightarrow 12$ pter; 11 pter $\rightarrow 11 \mathrm{q}$ $14:: 8$ p10 $\rightarrow$ 8pter; 12 qter $\rightarrow 12$ p10::11q14 $\rightarrow 11$ qter) was identified in a woman who experienced five abortions (Kotzot et al., 2001).

Karyotyping meiotic metaphase chromosomes from human oocytes and polar bodies has been crucial for in vitro fertilization (IVF) attempts. Cytogenetic studies on spontaneous abortions have clearly shown that chromosomal abnormalities constitute the major contributing factor to human embryo wastage and low rates of pregnancy following
IVF in women of advanced maternal age. Marquez et al. (1998) obtained a hybridization efficiency of $95.2 \%$ with SKY analysis on human MII oocytes, a much higher rate than the previous frequency of $35.4 \%$ accomplished using banding techniques and a little higher than the $81.3 \%$ achieved by FISH. Thus, SKY was judged as the most appropriate method for the cytogenetic analysis of female gametes, since ideally all the chromosomes are simultaneously and distinctively labeled and identified (Pellestor et al., 2005). Furthermore, the observation of balanced chromatid predivision in fresh, non-inseminated metaphase II oocytes suggested that chromatid predivisions contribute to the occurrence of aneuploidy in human oocytes (Sandalinas et al., 2002).

Recently, a great improvement has been achieved for the characterization of chromosome aberrations by the combination of high resolution Array CGH and SKY analyses. A healthy father and his disabled son both showed an additional band on the long arm of chromosome 16 observed by conventional G-banding. SKY analysis revealed a balanced $t(4 ; 16)$ in the father and an unbalanced $\operatorname{der}(16) t(4 ; 16)$ in the son. Translocation breakpoints and the size of the deletion and the translocated fragments were determined by Array CGH analysis using a custom-made $6.000 \mathrm{BAC}$ array followed by FISH experiments with locus-specific probes (Fig. 1, Matthaei et al., 2005).

\section{Molecular cytogenetic diagnostics and research in leukemias and lymphomas}

SKY and FISH analysis of leukemias and lymphomas have been well accepted within the scientific community and also in diagnostic settings. In tumor cytogenetic laboratories G-banding and FISH analyses are being routinely applied side-by-side to determine chromosomal changes and tumor heterogeneity by studying metaphase chromosomes and uncultured interphase nuclei. In case of normal karyotypes or complex aberrations, investigations using SKY or M-FISH are performed in addition to resolve chromosome rearrangements. The identification of new translocations and cryptic changes initializes gene identification studies followed by the disclosure of signalling pathways that are involved in tumorigenesis.

Chromosome rearrangements, misclassified or undetected by standard cytogenetic techniques, were identified in numerous AML and ALL patients (Veldman et al., 1997; Calabrese et al., 2000b, 2002; Kelly et al., 2002; Mrozek et al., 2002). For instance, SKY analysis detected chromosomal aberrations in $7 \%$ of the analyzed AML samples with normal karyotypes, e.g. a cryptic 11q23 translocation and a minor monosomy 7 clone (Zhang et al., 2000; Hilgenfeld et al., 2001). Mohr et al. (2000) found an apparently new translocation $\mathrm{t}(7 ; 14)$ in two out of 39 AML and MDS patients. In the AML-M2 subgroup more than 70 chromosomal aberrations were identified in 37 patients, among them 17 new and 16 redefined unbalanced translocations. Two reciprocal translocations $\mathrm{t}(\mathrm{X} ; 3)(\mathrm{q} 24 ; \mathrm{p} 21)$ and $\mathrm{t}(11 ; 19)(\mathrm{q} 23 ; \mathrm{p} 13.1)$ were 


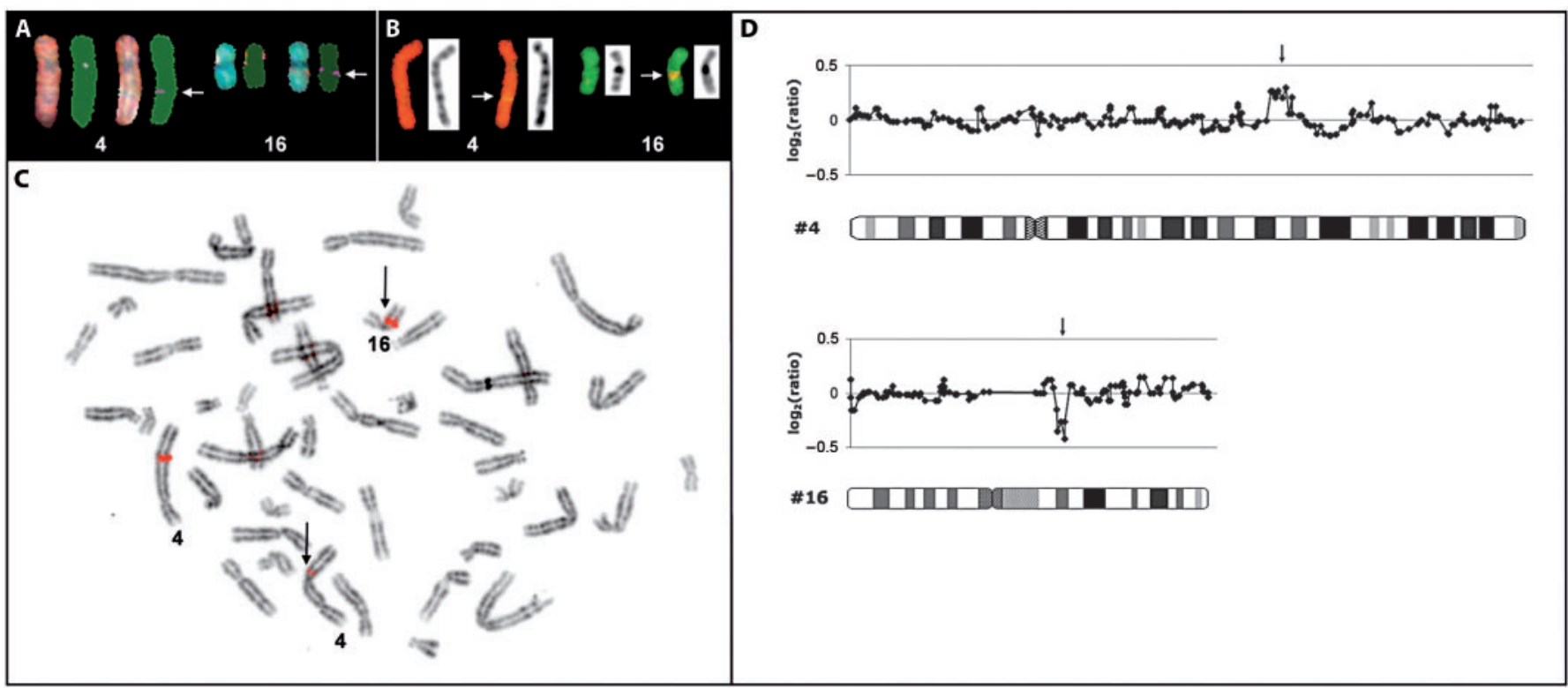

Fig. 1. Combined SKY, FISH and Array CGH analyses on metaphase chromosomes of the father and the propositus. More detailed information as well as the clinical phenotype can be found in the paper by Matthaei et al. (2005). (A) SKY revealed an reciprocal insertion (arrows) between chromosomes 4 and 16 in the father, which was confirmed by chromosomal painting (B). (C) Example of a split hybridization signal indicating that BAC RP11-52k8 (red) spans the telomeric breakpoint of the der(4) in chromosome band 4q28.1 (arrow) and thus also shows a hybridization signal (arrow) on the $\operatorname{der}(16)$ ins $(4 ; 16)$ (q26q28.1;q12.1q12.2). (D) Array-CGH analysis using DNA from the patient showing the unbalanced insertion $\operatorname{der}(16)$ ins $(4 ; 16)(\mathrm{q} 26 \mathrm{q} 28.1$; q12.1q12.2) on a chip with 6000 BACs indicating a gain of the chromosomal region $4 \mathrm{q} 26 \rightarrow \mathrm{q} 28.1$ and a loss of $16 \mathrm{q} 12.1 \rightarrow \mathrm{q} 12.2$ (arrows). Reprinted from Matthaei et al. (2005) with permission from Elsevier. found, which were missed by G-banding analysis (Hilgenfeld et al., 2001). A child, diagnosed with AML-M2 and characterized by the translocation $\mathrm{t}(8 ; 21)$ (q22; 22$)$ (AML1RUNX1T1), developed a therapy-related myelodysplastic syndrome (tMDS). A new chromosomal translocation $\mathrm{t}(2$; 8)(p23;p11.2) was detected by SKY analysis and the MYST3 gene on chromosome band $8 \mathrm{p} 11$ was found to be rearranged using FISH. MYST3, fused to an unidentified partner gene at chromosome band 2p23, may have caused an alteration in histone acetylation, resulting in the development of tMDS in this patient (Imamura et al., 2003). A new myeloid cell line, designated YSK-21, also carrying the balanced translocation $\mathrm{t}(8 ; 21)$, revealed in addition an unbalanced der(1)t $(1$; 17)(p36;q21). This unbalanced translocation was accompanied by a deletion of one allele and partial demethylation of the second allele of the tumor suppressor gene TP73 (1p36) and by a point mutation in one copy of the TP53 gene on 17q21. Infant AML with $\mathrm{X}$ chromosome disruption and $M L L$-gene translocation was reported in two cases, one with a translocation $\mathrm{t}(\mathrm{X} ; 11)$ and one with a complex translocation $\mathrm{t}(\mathrm{X} ; 3 ; 11)$. The identification of SEPT6 and the SEPTIN family members SEPT5 and SEPT9 as partner genes of the $M L L$ gene suggested a common pathway to leukaemogenesis (Slater et al., 2002). A young girl was found to be afflicted with aggressive acute monoblastic leukemia (AML) (M5b) with skin, lymph node, and bone marrow involvement. Cytogenetic analysis revealed three clones with different secondary chromosomal changes. Using SKY technology Stark et al. (2002) detected that all three clones orig- inated from a common clone that harbored the hidden primary and very poor prognostic translocation $t(10 ; 11)$ (p13;q23) or its derivatives, suggesting clonal evolution of the disease.

The translocation $\mathrm{t}(1 ; 19)(\mathrm{q} 21 \rightarrow \mathrm{q} 23$; $\mathrm{p} 13.3)$ involving the long arm of chromosome 1 and the short arm of chromosome 19 is usually associated with acute lymphoblastic leukemia. Tchinda et al. (2002) found a new translocation with one virtually identical breakpoint on chromosome band $19 \mathrm{p} 13$ and the other breakpoint on chromosome band $1 \mathrm{p} 13$ in two cases of myeloid neoplasms, a 13-month-old child with the diagnosis of acute monocytic leukemia (AML M5a), and a bone marrow sample of a 21-year-old woman with MDS, subtype refractory anemia with ringed sideroblasts (RARS) probably associated with a Fanconi anemia (FA).

Multiple chromosome rearrangements (MCRs) are seen in $5-10 \%$ of newly diagnosed patients with acute myeloid leukemia (AML) and $15-30 \%$ of patients with myelodysplastic syndromes (MDS), in particular in patients of old age, with previous exposure to radio- and/or chemotherapy and a short survival time (Lindvall et al., 2001). Some MCRs detected in AML were similar to MCRs described in MDS and often resulted in partial deletions of chromosomes 5, 7 and 17 and gains of chromosome 8. The chromosomal changes were complemented by gene expression data showing that the differentially expressed genes were located on chromosome arms 5q and 7q (Lindvall et al., 2004). 
Erythroid leukemia (ERL or AML-M6) is an uncommon subtype of acute myeloid leukemia awaiting further detailed characterization. Cigudosa et al. (2003) analyzed a homogeneous group of de novo AML-M6 patients and leukemia cell lines with an erythroid phenotype. Hypodiploidy, monosomies of chromosomes 7 or 18 and deletions of chromosome arm $5 \mathrm{q}$ were repeatedly found. Interestingly, MLL gene rearrangements were detected in $20 \%$ of the cases. Two novel, cryptic and recurrent translocations were described as translocation $\mathrm{t}(11 ; 19)(\mathrm{p} 11.2 ; \mathrm{q} 13.1)$ and translocation $\mathrm{t}(12 ; 21)(\mathrm{p} 11.2 ; \mathrm{q} 11.2)$. Thus, primary samples and cell lines shared three common breakpoints at 19q13.1,20q11.2, and 21q11.2. These data may contribute to the identification of genes involved in erythroleukemogenesis (Cigudosa et al., 2003).

At the present time tumor suppressor genes are being hunted for on the long arm of chromosome 5 . Knutsen et al. (2003) established two t-AML cell lines, which carry partial deletions on the long arm of chromosome 5 and may prove useful in the study of the mechanisms leading to the development of t-AML.

Gene amplifications have rarely been found in leukemias and lymphomas. A cell line with megakaryoblastic features that contains an amplification of the normal germline configuration of the $M L L$ gene was established and analyzed by Allen et al. (1998) from an AML patient. The first evidence for the amplification of the RUNX1 gene in MDS cases was provided by Kakazu et al. (1999). SKY analysis revealed that double minute chromosomes (DMINs) in AML and MDS patients were derived from chromosomes 8,11 and 19. The exact origins of the amplified sequences were finally determined using FISH with BAC DNA probes (Sait et al., 2002).

The power of the SKY technique was again demonstrated when stratified cohorts of childhood B-lineage acute lymphoblastic leukemias (B-ALLs) with more than 150 patients were re-evaluated subsequently to chromosome banding (Elghezal et al., 2001; Mathew et al., 2001; Nordgren et al., 2002). Twelve of 70 ALL patients showed prognostically unfavourable chromosomal aberrations that were missed before (Nordgren et al., 2002). Three novel translocations: a $\operatorname{der}(\mathrm{X}) \mathrm{t}(\mathrm{X} ; 5)(\mathrm{p} 11.4 ; \mathrm{q} 31)$, a der(21)t(X;21)(p11.4;p11.2) and a $t(X ; 9)(p 11.4 ; p 13)$ were found in four of ten patients with previously seen marker and derivative chromosomes (Mathew et al., 2001). Elghezal et al. (2001) found that altogether 83 chromosome aberrations went undetected or were not characterized using chromosome banding in two-thirds of 51 cases. A rearrangement of the PAX5 gene was identified in a case of pediatric ALL with the translocation $t(2$; 9)(p11.2;p13) as well as other non-recurrent translocations (Lu et al., 2002). Tumor cells from ALL patients with apparently normal karyotypes harboured genetic aberrations that are detectable using interphase FISH and SKY (Nordgren et al., 2001b). Also Mathew et al. (2001) identified three cryptic translocations: a $\mathrm{t}(7 ; 8)(\mathrm{q} 34 \rightarrow 35 ; \mathrm{q} 24.1)$, a $\mathrm{t}(13 ; 17)(\mathrm{q} 22$; q21) and a der(19)t(17;19)(q22;p13) in two of 20 pediatric ALL patients (10\%) with normal karyotypes. In contrast, the translocation $\mathrm{t}(12 ; 21)$ was not always picked up by SKY, depending on the lengths of the analyzed chromosomes. A non-random pattern of chromosomal changes was identified in 15 high hyperdiploid ( $>51$ chromosomes) childhood ALLs, which typically display a poor chromosome morphology. The numerical changes, with chromosomes $\mathrm{X}, 21$, $14,17,6,18,4$, and 10 being most frequently gained, some of which, i.e. +4 and +10 , have been suggested to be prognostically important, were partly misinterpreted in 12 of the 15 ALL patients using G-banding. Five rearrangements $[\operatorname{der}(1) \mathrm{t}(1 ; 14)(\mathrm{q} 32 ; \mathrm{q} 21), \quad \operatorname{der}(2) \mathrm{t}(2 ; 8)(\mathrm{q} 36 ; ?), \quad \operatorname{der}(3) \mathrm{t}(2 ; 3)$ $(\mathrm{q} 21 ; ?), \operatorname{der}(8) \mathrm{t}(8 ; 14)(? ; ?)$, and $\mathrm{t}(9 ; 21)(\mathrm{q} 12 ; \mathrm{q} 22)]$ had previously not been reported in ALL (Nordgren et al., 2001a).

Mature B-cell acute lymphoblastic leukemia (ALL) is typically associated with the FAB-L3 morphology and a rearrangement of the $M Y C$ gene. In contrast, infantile B-cell ALL is generally characterized by a rearrangement of the $M L L$ gene, an immature pro-B-cell phenotype, and CD10 negativity. Two unusual cases of infantile B-ALL with nonL3 morphology and expressing a mature B-cell phenotype were described by Tsao et al. (2004). These patients may represent a distinct subset showing the translocation $\mathrm{t}(9 ; 11)$ with an $M L L$ gene rearrangement but without rearrangements of the MYC gene. The tumor cells of a patient with refractory anaemia with excess of blasts (RAEB) showed a complex karyotype with multiple copies of the MLL gene resulting from an unbalanced translocation $\operatorname{der}(20) t(11 ; 20)$ and three unbalanced derivative chromosomes der(11). The patient died 6 months after diagnosis, thus indicating the severe prognosis of $M L L$ gene amplifications (Calabrese et al., 2003).

TEL/ETV6 was the first transcription factor identified that is specifically required for hematopoiesis within the bone marrow. Odero et al. (2001) identified six new TEL/ ETV6 translocation partners in chromosome bands 1p36, 4q22, 6p21, 6q25, 12q24, and 17q12. Lu et al. (2002) found a translocation $\mathrm{t}(12 ; 14)(\mathrm{p} 13 ; \mathrm{q} 32)$ and confirmed the fusion of TEL/ETV6 with IGH for the first time in a pediatric ALL patient. Three other novel TEL/ETV6 partner breakpoints were described by Nordgren et al. (2002) on chromosome bands 1p32, 1q41, 8q24 and 21p12.

Complex chromosome aberrations often occur in chronic myeloid leukaemia (CML) patients undergoing a blastic crisis. A patient with a Ph-positive CML underwent allogeneic peripheral blood stem cell transplantation. Several months later the disease progressed towards a blastic crisis and the karyotype was determined to be complex with a $\mathrm{t}(20 ; 21)(\mathrm{q} 11 ; \mathrm{q} 22)$ involving the RUNX1 gene and translocations and insertions of chromosomes 8 and 1 in addition to the translocation $\mathrm{t}(9 ; 22)$ (Calabrese et al., 2000a). Understanding the complex aberrations occurring in $5-10 \%$ of the CML patients will facilitate the interpretation of complex FISH signal patterns in interphase nuclei during follow-up investigations. We have identified a complex Ph translocation and additional aberrations in a CML patient using SKY. Chromosomes 6, 9, 11, 13, and 22 contributed to the complex translocations whereas chromosome 7 was lost and chromosomes 3 and 12 were involved in a reciprocal translocation (Fig. 2). 


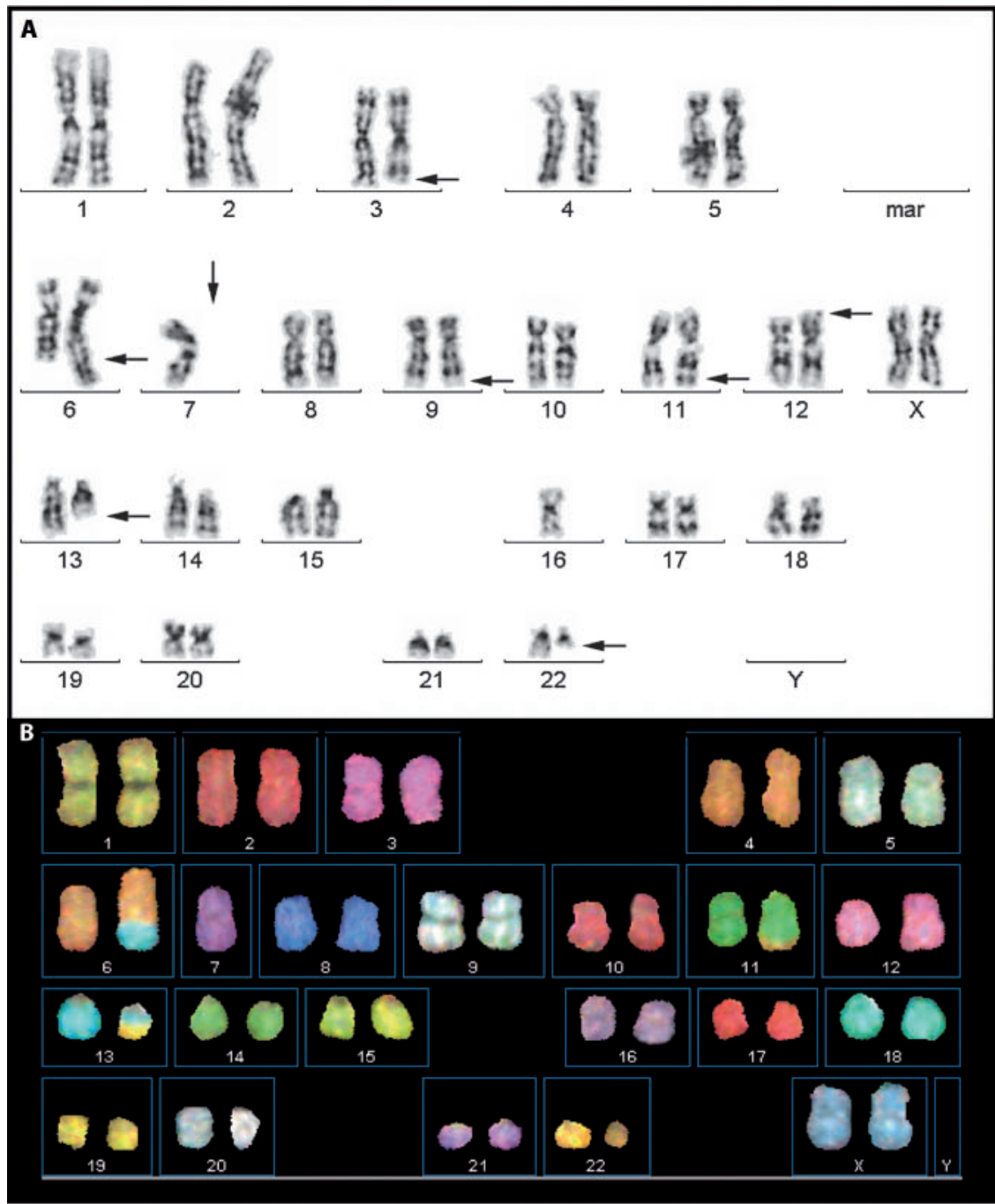

Fig. 2. Sequential G-banding and SKY analysis of a tumor cell obtained from a CML patient. (A) Chromosomes 3, 6, 7, 11, 12, 13 and 22 showed abnormal banding patterns or were lost, but chromosome 9 appeared to be normal. (B, C) SKY revealed the loss of chromosome 7 , the reciprocal translocation $\mathrm{t}(3 ; 12)(\mathrm{q} 27 ; \mathrm{p} 13)$ and the complex variant $\mathrm{Ph}$ translocation $\mathrm{t}(6 ; 11 ; 9 ; 22 ; 13)(\mathrm{q} 25 ; \mathrm{q} 25$; $\mathrm{q} 34 ; \mathrm{q} 11 ; \mathrm{q} 14)$. The patient was analyzed in cooperation with Prof. Dr. med. Bernd Dörken, Charité - Universitätsmedizin Berlin, Campus Virchow - Klinikum, Medizinische Klinik mit Schwerpunkt Hämatologie und Onkologie, Berlin, Germany.
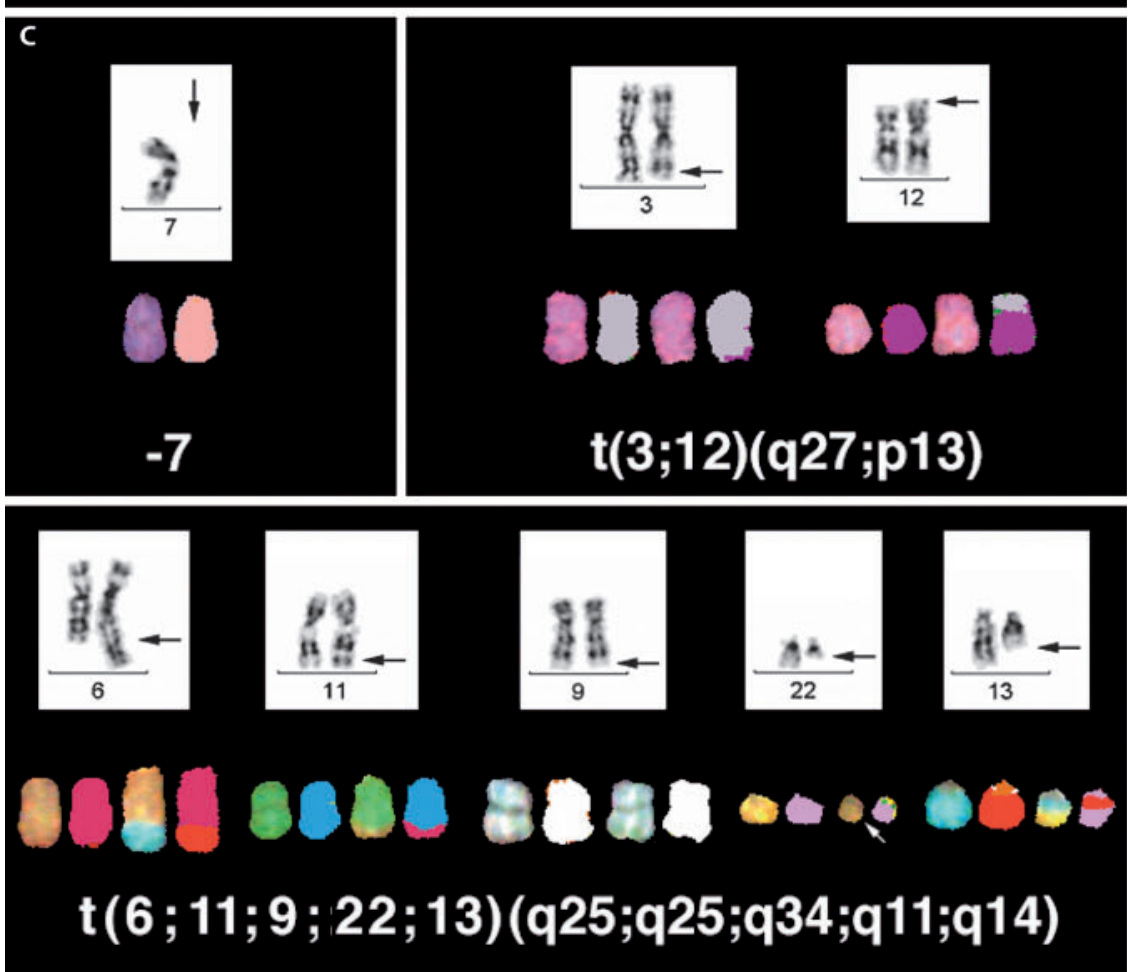
The NPM-ALK fusion gene as a result of the chromosome translocation $\mathrm{t}(2 ; 5)(\mathrm{p} 23 ; \mathrm{q} 35)$ is usually found in lymphomas with a $\mathrm{T}$ cell or null phenotype. However, Adam et al. (2003) described the same fusion gene with respect to a complex chromosome translocation of a plasmablastic lymphoma of unequivocally proven B-cell lineage (Adam et al., 2003).

The translocation $t(14 ; 18)(\mathrm{q} 32 ; \mathrm{q} 21)$, recombining the immunoglobulin heavy chain (IGH) gene on chromosome 14 with the B-cell leukemia/lymphoma 2 (BCL2) gene on chromosome 18 , is a typical feature of follicular lymphomas (FLs). The progression of FL may be associated with multiple secondary IGH translocations and insertions (Nomura et al., 2005). Diffuse large B-cell lymphoma (DLBCL), a histologically well-defined subset of nonHodgkin lymphomas, revealed new recurring breakpoints, translocations, and regions of gains and losses, namely, gain of chromosomal regions $2 \mathrm{p} 22 \rightarrow \mathrm{p} 13,2 \mathrm{q} 21$, $3 \mathrm{q} 27 \rightarrow \mathrm{q} 29,9 \mathrm{p} 24 \rightarrow \mathrm{p} 11,13 \mathrm{q} 22 \rightarrow \mathrm{q} 34,18 \mathrm{q} 21$, and $19 \mathrm{q} 11 \rightarrow \mathrm{q} 13$ and loss of chromosomal bands $6 \mathrm{q} 11 \rightarrow \mathrm{q} 13$ and $18 \mathrm{p} 11$. SKY analysis identified three sites (2q31, 3q27, 7q22) significantly associated with advanced-stage disease or poor treatment response (Nanjangud et al., 2002). Also, a new translocation partner for the $14 \mathrm{q} 32$ translocation was found on 22q13 in a non-Hodgkin's lymphoma with complex chromosomal abnormalities (Kakazu et al., 2000).

Cell lines, derived from sporadic Burkitt Lymphoma (BL) and negative for Epstein-Barr virus (EBV), were found to contain the translocation $\mathrm{t}(8 ; 14)(\mathrm{q} 24 ; \mathrm{q} 32)$ involving the $c-m y c$ gene and the IGH locus. Additionally, the complex translocations $\mathrm{t}(7 ; 8 ; 14)(\mathrm{q} 11.2 ; \mathrm{q} 24 ; \mathrm{q} 32)$ and $\mathrm{t}(8 ; 14 ; 18)(\mathrm{q} 24$; q32;q23) were described, which resulted in transposition of $M Y C$ sequences in a new genomic configuration. The tumorigenicity of the cell lines was tested by injecting cells intraperitoneally into SCID mice. One cell line, which contained a partial duplication of the long arm of chromosome 1 , was highly tumorigenic suggesting that this region harbors gene(s) associated with tumor cell invasiveness (Zimonjic et al., 2001).

Blastic natural killer cell leukaemia/lymphoma (bNKL/ L) has been considered to constitute a distinct entity with complex cytogenetic abnormalities. Kuroda et al. (2000) detected a translocation $\mathrm{t}(4 ; 14)(\mathrm{q} 12 ; \mathrm{q} 11.2)$ in a patient afflicted with aggressive NK cell leukemia/lymphoma. The chromosomal band $14 \mathrm{q} 11.2$ is a recurring breakpoint in T-cell non-Hodgkin lymphoma, and is also the locus of the $\delta$ chain of the T-cell receptor. Jyoko et al. (2002) described the karyotype of a patient as $44, \mathrm{X},-\mathrm{Y},-8, \operatorname{der}(10) \mathrm{t}(8 ; 10)$ (q11; $\mathrm{p} 11), \operatorname{der}(11) \mathrm{t}(\mathrm{Y} ; 11)(\mathrm{p} 11 ; \mathrm{q} 13),-13, \operatorname{der}(16) \mathrm{t}(11 ; 16)(\mathrm{q} 13 ; \mathrm{p} 13)$, $\mathrm{i}(17)(\mathrm{q} 10),+20, \operatorname{der}(20) \mathrm{t}(4 ; 20$ (?;p11)x2. The unbalanced translocations involving the breakpoints at $10 \mathrm{p} 11$ and $11 \mathrm{q} 13$ were also found in two previous cases. Additional patients should be studied to facilitate the elucidation of the pathogenesis of NKL/L.

Malignant non-Hodgkin lymphoma (NHL) cell lines derived at the Ontario Cancer Institute (OCI), Toronto, revealed 87 breakpoints, which clustered at chromosome bands 1q21, 7p15, 8p11, 13q21, 13q32, 14q32, 17q11, and $18 \mathrm{q} 21$. The SKY analysis led to the identification of 60 translocations, including five that were recurring, translocations $\mathrm{t}(8 ; 14)(\mathrm{q} 24 ; \mathrm{q} 32), \mathrm{t}(14 ; 18)(\mathrm{q} 32 ; \mathrm{q} 21), \mathrm{t}(4 ; 7)(\mathrm{p} 12 ; \mathrm{q} 22), \mathrm{t}(11 ; 18)$ (q22; $\mathrm{q} 21)$, and $\mathrm{t}(3 ; 18)(\mathrm{q} 21 ; \mathrm{p} 11)$. Furthermore, the sources of all marker chromosomes were determined and 10 chromosomes that were classified as normal by G-banding were found to be rearranged (Mehra et al., 2002). For pathogenetic investigations of how secondary non-Hodgkin lymphomas may occur in patients treated for Hodgkin lymphoma (HL), a cell line derived from a patient afflicted with a DLBCL with relapsing HL was thoroughly investigated using G-banding, CGH and SKY analysis (Amini et al., 2002). Besides a mutation of the TP53 gene, the cell line carried a complex karyotype including regional amplifications of chromosome bands $1 \mathrm{q} 12 \rightarrow \mathrm{q} 23,3 \mathrm{q} 27,11 \mathrm{q} 21 \rightarrow \mathrm{q} 23$ and 18q21. The authors hypothesized that NHL occurred after treatment for HL either as a chemotherapy-induced tumor or as a result of the HL progression.

The first complete Hodgkin disease (HD) karyotype obtained from cell lines was published by MacLeod et al. (2000). The authors reported for the first time a genomic rDNA rearrangement in tumor cells. They also identified multiple 'jumping translocations' (JT). These data suggested that tumorigenic rearrangements may be facilitated in HD by 'hitchhiking' along with mobile DNA repeat sequences resulting in gene rearrangements at chromosome arm 9p (MacLeod et al., 2000).

Obtaining karyotypic information on multiple myeloma (MM) cells is difficult due to low mitotic activity of the malignant plasma cells. Rao et al. (1998) identified several novel recurring sites of breakage on chromosome bands 3q27, $17 \mathrm{q} 24 \rightarrow \mathrm{q} 25$, and $20 \mathrm{q} 11$. New recurrent translocations included $\mathrm{t}(12 ; 14)(\mathrm{q} 24 ; \mathrm{q} 32)$ and $\mathrm{t}(14 ; 20)(\mathrm{q} 32 ; \mathrm{q} 11)$ (Rao et al., 1998), $\mathrm{t}(14 ; 16)(\mathrm{q} 32 ; \mathrm{q} 22-23), \mathrm{t}(9 ; 14)(\mathrm{p} 13 ; \mathrm{q} 32)$, and $\mathrm{t}(6 ; 8)$ (p10;q10) (Sawyer et al., 1998), t(14;22)(q32;q11,12), t(11;22) (q13;q13), and $\operatorname{der}(7) \mathrm{t}(7 ; 7)(\mathrm{p} 15,22 ; \mathrm{q} 22,32)$ (Sawyer et al., 2001, 2005). Furthermore, the characterization of 100 primary MMs showed that the loss of $8 p$, found in $23 \%$ of the patients, may occur by multiple whole-arm translocations, thus indicating a new pathway for the loss of a specific chromosome region in MM (Sawyer et al., 2001). The same authors also reported on jumping segmental duplications involving the chromosome region $1 \mathrm{q} 12 \rightarrow \mathrm{q} 21$ and adjacent bands (Sawyer et al., 2005).

In summary, the use of SKY substantially improves the precision of karyotype analysis of malignant cells, which in turn leads to a more accurate assessment of the genotypic abnormalities in those cells (Rowley et al., 1999).

\section{Identification of recurrent translocations and breakpoints in mesenchymal tumors}

Comparable to leukemias and lymphomas, mesenchymal tumors have been characterized by chromosome translocations leading to gene fusions. Importantly, the identifi- 
cation of specific rearrangements contributes to the differential diagnosis and subsequently helps for therapy stratifications of these tumors.

For instance, benign fibro-osseous lesions of bone (BFOL) comprise a group of clinically distinct entities with significant histologic overlap and often occur in children and adolescents. Sixteen cases of BFOL including ossifying fibromas, osteofibrous dysplasias, and fibrous dysplasias revealed clonal aberrations fusing breakpoints on chromosome bands Xq26 and 2q33, and carried multiple copies of chromosomes 8, 12, and/or 21 (Parham et al., 2004).

In case of lipoblastomas or infantile lipomas, a rare adipose tumor occurring exclusively in childhood, a chromosomal rearrangement involving the long arm of chromosome 8 can assist in the differential diagnosis from myxoid or well differentiated liposarcoma. Preliminary data indicated that the PLAG1 gene on 8q12 is affected (Astrom et al., 2000). Using SKY, complex aberrations were also resolved in lipoblastomas: 92,XXYY,t $(7 ; 8)(\mathrm{p} 22 ; \mathrm{q} 11.2) \times 2[8] / 46, \mathrm{XY}$ [16] and 46,XY,r(8),del(13)(q12),der(16)ins(16;8)(q22;q24 q11.2)[cp13]/46,XY[7] confirming the involvement of chromosome band 8q11.2 $\rightarrow$ q12 (Chen et al., 2000).

Ewing's sarcoma (ES) is an aggressive neoplasm which typically arises within the extremities or pelvis of a child or adolescent. The accurate and rapid diagnosis of ES is essential for clinical management. Since ES of the skull is rare, only accounting for approximately $6 \%$ of all cases, the consistency of the translocations such as the common translocation $\mathrm{t}(11 ; 22)(\mathrm{q} 24 ; \mathrm{q} 12)$ and the less frequent translocations $\mathrm{t}(21 ; 22), \mathrm{t}(7 ; 22), \mathrm{t}(17 ; 22)$ and $\mathrm{t}(2 ; 22)$ indicated the diagnostic value of molecular cytogenetic analysis (Carlotti et al., 1999). Secondary chromosomal changes, e.g. chromosome numbers in excess of 50, may be associated with a poor prognosis for ES patients (Kullendorff et al., 1999) and may indicate tumors that are less responsive to treatment (Zielenska et al., 2001). Shing et al. (2002) identified a novel, unbalanced translocation involving chromosomes 16 and 17 in three of eight ESs leading to the loss of the long arm of chromosome 16 and the short arm of chromosome 17. Recurrent breakpoints were located at chromosome bands 16p11.2, 16q11.1, 17p11.2 and 17q11.2.

Osteosarcomas (OSs) are often highly aneuploid. A total of 531 rearrangements were identified by SKY in 14 primary OS tumors and four OS cell lines, of which 300 breakpoints were assigned to a specific chromosome band (Bayani et al., 2003). 29\% of the breakpoints were located in centromeric or pericentromeric regions leading to wholearm chromosome translocations. The highest frequency of alterations included the gain of chromosome bands $8 \mathrm{q} 23 \rightarrow \mathrm{q} 24$ and $17 \mathrm{p} 13 \rightarrow \mathrm{p} 11$ and rearrangements of the long arm of chromosome 20. Specific sequences mapping to these chromosome regions will likely have a role in the development and progression of OS. A detailed characterization and quantification of the amplicons on the short arms of chromosomes 6 and 17 was carried out by FISH analysis, in addition to the detection of several novel recurrent breakpoint clusters and reciprocal translocations (Lau et al., 2004).
Proximal-type epithelioid sarcomas are characterized by an aggressive clinical course and rhabdoid morphology. They cause serious diagnostic dilemmas, being easily misdiagnosed as a variety of other malignant neoplasms. The identification of two cases with a similar translocation $t(10$; 22) suggested a role for one or more genes on chromosome 22 in the pathogenesis of this tumor. A gain of the long arm of chromosome 8 including the MYC gene was also a frequent event (Lualdi et al., 2004).

Rhabdomyosarcoma in children is a 'small round blue cell tumor' that displays skeletal muscle differentiation. A surprisingly high level of chromosomal changes was detected in rhabdomyosarcoma cell lines of embryonal and of alveolar origin (ERMS and ARMS) (Pandita et al., 1999), including translocations involving chromosomes 1 and 15 and chromosomes 2 and 15 (Roberts et al., 2001). Reciprocal translocations that generate the fusion gene PAX3-FOXO1A $(\mathrm{t}(2 ; 13))$ or PAX7-FOXO1A $(\mathrm{t}(1 ; 13))$ were described in ARMS. Cell lines positive for these fusion genes were found to be highly complex with a wide range of chromosome numbers showing more than 50 chromosome rearrangements, amplification of the hybrid genes, more than 20 DNA changes detected by conventional CGH, and between 8 and 21 gene copy changes seen by microarray CGH, also confirming the previously reported high-level amplification of MYCN (Rodriguez-Perales et al., 2004).

Gastrointestinal stromal (pacemaker cell) tumors (GIST/ GIPACTs) are known for activating KIT mutations and specific chromosome rearrangements. Cytogenetic and SKY analysis of 10 GIST/GIPACTs revealed clonal abnormalities in eight tumors, such as terminal deletions on chromosome arm $1 \mathrm{p}$ and losses of chromosomes 14 and/or 22. Thus, the role of chromosomal rearrangements in the pathogenesis of GIST/GIPACTs may be more complex than previously recognized (Andersson et al., 2002).

The fusion of the nuclear receptor TEC to various $\mathrm{NH}_{2}-$ terminal partners was found in extraskeletal myxoid chondrosarcomas (EMCs). Clonal chromosome abnormalities included a translocation $\mathrm{t}(9 ; 22)(\mathrm{q} 22 ; \mathrm{q} 12)(E W S-T E C)$, variant translocations, such as $\mathrm{t}(9 ; 17)(\mathrm{q} 22 ; \mathrm{q} 11 \rightarrow \mathrm{q} 12), \mathrm{t}(7 ; 9 ; 17)$ (q32;q22;q11), and $\mathrm{t}(9 ; 15)(\mathrm{q} 22 ; \mathrm{q} 21)$ and a deletion del(22) $(\mathrm{q} 12 \rightarrow \mathrm{q} 13)$. Additional abnormalities consisted of a gain of the long arm of chromosome 1 and trisomies of chromosomes 7, 8, 12, and 19 (Sjogren et al., 2003b).

Rare tumors have not been analyzed as intensely as common cancers. An unbalanced translocation between chromosomes 1 and $\mathrm{X}$ and a trisomy 8 were detected in a pleuropulmonary blastoma (PPB) (Barnard et al., 2000). This malignant intrathoracic pediatric tumor arises from the lung, pleura, or mediastinum.

In some instances tumor histogenesis still remains unclear today, for instance for alveolar soft-part sarcoma (ASPS). Using SKY, an unbalanced translocation der(17) $t(X ; 17)(p 11.2 ; q 25)$ was identified (Joyama et al., 1999). Recently, molecular analysis determined the fusion product between TFE3 (a transcription factor gene) at chromosome band Xp11 and a novel gene designated as ASPSCR1 at chromosome band $17 \mathrm{q} 25$. 


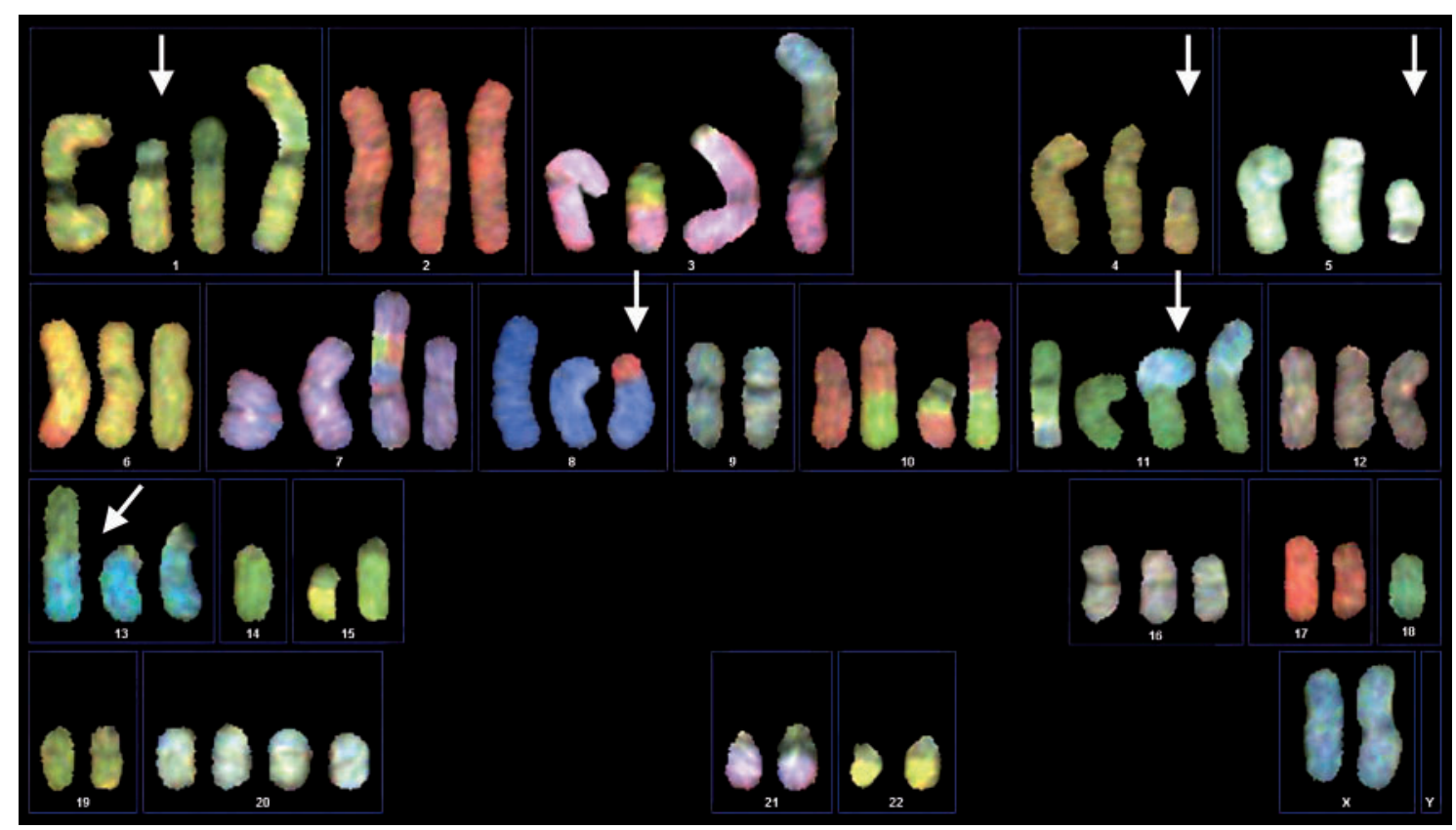

Fig. 3. Representative SKY karyotype of the HNSCC cell line scc078. Arrows indicate the whole chromosome arm translocations, reading from 1 to X: (1q;18p), (4p;12p), (5p;18p), (8q;10p), 2x (11q;Xq) and (11q;13q). Tissue-specific differences of centromeric breakage between squamous cell carcinomas and adenocarcinomas were reported by Hermsen et al. (2005). Reprinted from Hermsen et al. (2005) with permission from Nature Publishing Group.

These findings also underline the importance of molecular cytogenetic applications for the study of rare tumors paving the road for improved patient care based on individual genotype-phenotype correlations.

\section{SKY analysis of sporadic and familial epithelial cancers}

The next decennial task for scientists and physicians is to implement the combination of genetic profiling and gene expression analysis as the new gold standard into tumor diagnostics and prognostics in order to improve medical service and to predict clinical courses for cancer patients.

\section{Chromosome aberrations detected in squamous cell} carcinomas

Squamous cell carcinomas of the head and neck (HNSCC) arise through a multistep process of genetic alterations as a result of exposure to environmental agents such as tobacco smoke, alcoholic beverages, and viruses, including human papillomavirus (HPV).

A striking feature of HNSCC is frequent breaks in centromeric regions resulting in whole arm translocations and isochromosome formation (Fig. 3). In contrast to adenocarcinomas, HNSCCs showed that DNA sequences of both centromeres contributed to the formation of a fused centromere (Hermsen et al., 2005). The karyotypes of oral squamous cell carcinoma (OSCC) are near-triploid and contain multiple structural and numerical abnormalities (Reshmi et al., 2004). Cell lines derived from HNSCC and from premalignant oral epithelium revealed amplifications at 3 q $26 \rightarrow$ q 27 in $42 \%$ of the cases (Singh et al., 2001). Losses of chromosomes 15 and 22 and gains of chromosomes 10 and 20 correlated significantly with an unfavourable outcome in primary untreated HNSCCs (Bergamo et al., 2005). The comprehensive approach of CGH, SKY and expression analysis showed that several deregulated genes mapped to regions of genomic imbalance and chromosomal rearrangements (Squire et al., 2002). An HPV16-infected cell line cultured from a tongue-base SCC revealed multiple integrated viral DNA copies in blocks throughout the genome. Subsequent chromosome breakage studies suggested that the observed viral-cellular integration sites may have occurred within common fragile sites (CFSs). Additional studies using RT-PCR for viral transcripts showed oncoprotein expression from episomal and integrated viral sequences (Ragin et al., 2004). Akervall et al. (2004) studied cell lines derived from HNSCC that were either cisplatin sensitive or resistant. Distinct differences in the genetic and expression profiles indicated that cisplatin resistance is multifactorial and that novel drug targets must be defined to improve tumor response.

Angiosarcoma of the head and neck most commonly involves the skin of the scalp or face; primary involvement of the sinonasal region is exceedingly rare. Complex chromosomal abnormalities with the presence of multiple hypodiploid clones, together with several near-triploid to near-tetraploid clones showing structural abnormalities of chromo- 
somes $1,3,4,9,14,16,17,18$, and 22 were described in a patient with sinonasal angiosarcoma complicated with marrow involvement (Wong et al., 2001).

A balanced translocation $\mathrm{t}(3 ; 7)(\mathrm{p} 25 ; \mathrm{q} 34)$ and a dicentric chromosome translocation $\operatorname{dic}(15 ; 22)(\mathrm{p} 11 ; \mathrm{p} 11)$ were found as the only abnormalities in a patient with a minimally invasive follicular thyroid carcinoma (FTC). This study represented the second case of FTC where 3p25 is involved in a balanced translocation supporting the existence of a gene locus in this region which may be involved in the tumorigenesis of thyroid carcinomas (Lui et al., 2000).

The molecular cytogenetic characterization and comparison of squamous cell carcinoma (SCC) and adenocarcinoma (AC) as subtypes of non-small-cell lung cancer (NSCLC) indicated common and distinct genetic changes. Hierarchical clustering simulation depicted gains of chromosomal regions $2 \mathrm{p} 13 \rightarrow \mathrm{p} 11.2,3 \mathrm{q} 25 \rightarrow \mathrm{q} 29,9 \mathrm{q} 13 \rightarrow \mathrm{q} 34,12 \mathrm{p}$, $12 \mathrm{q} 12 \rightarrow \mathrm{q} 15$ and $17 \mathrm{q} 21$, and loss of the short arm of chromosome 8 in preferential association with SCC pathogenesis. Recurring rearrangements involved translocations $t(1 ; 13)$, $\mathrm{t}(1 ; 15), \mathrm{t}(7 ; 8), \mathrm{t}(8 ; 15), \mathrm{t}(8 ; 9), \mathrm{t}(2 ; 17)$ and $\mathrm{t}(15 ; 20)$ (Sy et al., 2004b), aberrations characteristic for AC are shown below.

\section{Chromosome aberrations detected in adenocarcinomas}

A comparison between squamous cell carcinomas and adenocarcinomas by analyzing chromosome aberrations using Array CGH, SKY and FISH analyses was performed by Hermsen et al. (2005). The identification of centromeric breaks associated with whole arm translocations in adenocarcinoma and squamous cell carcinoma cell lines revealed that whole arm translocations were more frequent in squamous cell carcinomas (112 in nine cell lines and 9 in one short-term culture) than in adenocarcinomas (13 in seven cell lines) and most often resulted in copy number alterations. Array CGH analysis demonstrated that in all squamous cell carcinomas and in most adenocarcinomas the breakpoints of unbalanced whole arm translocations occurred between the two clones flanking the centromeres. However, FISH with centromeric probes revealed that in squamous cell carcinomas the marker chromosomes with whole arm translocations contained centromeres comprised of material from both participating chromosomes, while in adenocarcinomas centromeric material from only one of the chromosomes was present. These observations support the hypothesis that different mechanisms of centromeric instability underlie the formation of chromosomal aberrations in adenocarcinomas versus squamous cell carcinomas (Hermsen et al., 2005). Another comparison between SCC and $\mathrm{AC}$ was performed for NSCLC. Common events of gains of chromosome regions $1 \mathrm{q} 21 \rightarrow \mathrm{q} 24,5 \mathrm{p} 15 \rightarrow \mathrm{p} 14$, and $8 \mathrm{q} 22 \rightarrow \mathrm{q} 24.1$, and loss of bands $17 \mathrm{p} 13 \rightarrow \mathrm{p} 12$ were seen in both groups. The gain of the long arm of chromosome 8 was a frequent finding. In contrast to the translocations $t(7 ; 8)$, $\mathrm{t}(8 ; 15)$, and $\mathrm{t}(8 ; 9)$, the translocation $\mathrm{t}(8 ; 12)(\mathrm{q} 21 \rightarrow \mathrm{q} 22$; $\mathrm{q} 22 \rightarrow \mathrm{q} 24$ ) was exclusively found in AC tumors (Sy et al., 2004b). SKY analysis also uncovered chromosomal aberrations in AC lung tumors obtained from women who were lifelong nonsmokers. A ploidy status of hypertetraploidy was found with recurring derivative translocations involving chromosome arms 3q, 8q, 12q, 15q, 22q, and Xq (Sy et al., 2004a).

The diagnosis of a benign salivary basal cell adenoma was made of an unencapsulated, but well-demarcated, firm and lobular tumor removed from the lower and superficial part of the left parotid gland. G-banding and SKY-analysis revealed the karyotype 46,XX,der(7)t(7;13)(p15;q32), der (13)inv(13)(q12q32)t(7;13)(p15;q32). The only common abnormality of the so far published cases is one or two extra copies of chromosome 8 . It remains to be determined if the translocation $t(7 ; 13)$ and/or inv(13) are recurrent in basal cell adenomas (Sjogren et al., 2003a).

Hepatocellular carcinomas (HCC) carry chromosome aneuploidy ranging from near-diploid to hyperhexaploid karyotypes. Chromosome regions $1 \mathrm{p} 13 \rightarrow \mathrm{q} 21,8 \mathrm{p} 12 \rightarrow \mathrm{q} 21$, $17 \mathrm{p} 11 \rightarrow \mathrm{q} 12,17 \mathrm{q} 22$, and $19 \mathrm{p} 10 \rightarrow \mathrm{q} 13.1$ were involved in multiple rearrangements. Predominantly pericentromeric breakpoints clustered in chromosome bands $2 \mathrm{q} 33 \rightarrow \mathrm{q} 34$, $3 \mathrm{p} 13 \rightarrow \mathrm{q} 12,4 \mathrm{p} 14 \rightarrow \mathrm{q} 12,5 \mathrm{p} 10 \rightarrow \mathrm{q} 11,7 \mathrm{p} 12 \rightarrow \mathrm{q} 11,10 \mathrm{q} 10 \rightarrow \mathrm{q} 11$, $11 \mathrm{q} 10,11 \mathrm{q} 13 \rightarrow \mathrm{q} 21,12 \mathrm{q} 10 \rightarrow \mathrm{q} 13,12 \mathrm{q} 22 \rightarrow \mathrm{q} 23,13 \mathrm{q} 10 \rightarrow \mathrm{q} 14$, $15 \mathrm{q} 10,16 \mathrm{q} 10 \rightarrow \mathrm{q} 13,18 \mathrm{p} 11 \rightarrow \mathrm{q} 11,20 \mathrm{p} 11 \rightarrow \mathrm{q} 13.1,21 \mathrm{q} 10$, and 22q10. Correlating the tumor size and the number of aberrations, a significantly higher number of structural changes was found in tumors larger than $4 \mathrm{~cm}$. Rearrangements such as translocations $\mathrm{t}(1 ; 8), \mathrm{t}(1 ; 11), \mathrm{t}(1 ; 19)$, and $\mathrm{t}(17 ; 21)$ that were identified in both primary tumors and cell lines might represent markers that reflect proliferative advantages (Wong et al., 2000). Another set of HCC cell lines revealed the following recurrent translocations: $\mathrm{t}(\mathrm{X} ; 11), \mathrm{t}(1 ; 10), \mathrm{t}(4 ; 16)$, $\mathrm{i}(5)(\mathrm{p} 10), \mathrm{t}(7 ; 21), \mathrm{t}(8 ; 17), \mathrm{t}(9 ; 22), \mathrm{i}(10)(\mathrm{p} 10), \mathrm{t}(14 ; 20), \mathrm{t}(16$; $22)$, and $t(17 ; 19)$. It was noteworthy that consistent chromosome 10 aberrations, in particular $\mathrm{t}(1 ; 10)(\mathrm{q} 10 ; \mathrm{p} 10)$, were detected in all four cell lines and that microsatellite analysis indicated a common deleted region of $10 \mathrm{q} 23 \rightarrow \mathrm{q} 26$ (Pang et al., 2000, 2002). FISH mapping with BACs narrowed a breakpoint on chromosome 19 to the region of $19 \mathrm{p} 13.12 \rightarrow$ p12. Expression analysis revealed the single downregulated gene ACP5 (tartrate-resistant acid phosphatase type 5) on chromosome arm 19p (Chan et al., 2005). A gain of the long arm of chromosome 1 and rearrangements of chromosome 1 involving pericentromeric breakpoints are consistent findings in human HCC. Hypomethylation of satellite 2 (Sat2) DNA in 1q12 was found by Southern blotting using methyl-sensitive enzyme digestion in strong correlation with chromosome breakpoints in band 1q12 and gains of the long arm of chromosome $1(P<0.001)$. Of particular interest was the finding of Sat2 DNA hypomethylation in several adjacent nontumorous liver tissues. Thus, Sat 2 demethylation may contribute early on to the progression of liver carcinogenesis (Wong et al., 2003). Information on the clonal relationship between tumor nodules in patients diagnosed with HCC holds prognostic significance for the prediction of recurrence and postoperative treatment. Wong et al. (2005) found tumor nodules in $83.3 \%$ of the analyzed cases to cluster concordantly. The development of drug resistance either at the onset or during the course of treatment was linked to aberrations on chromosome 10 and position- 
al profiling suggested the candidate gene ECHS1 (Hu et al., 2004).

To identify chromosomal translocations specific to gastric cancer (GC), SKY analysis was performed on established cell lines and cancerous ascitic fluids. Chromosome 8 was the most frequently involved in rearrangements $(65$ breaks), followed by chromosomes 11 (53), 1 (49), 7 (46), 13 (37), 3 (36), 17 (33), and 20 (29). Frequent breakpoints were detected in chromosome bands 8q24.1 (30 breaks), 11q13 (29), 13q14 (16), 20q11.2 (14), 7q32 (13), 17q11.2 (13), 18q21 (12), 17q23 (9), 18q11.2 (9). SKY analysis identified a total of 242 chromosomal rearrangements including 190 reciprocal and non-reciprocal translocations. The recurrent combinations of chromosome bands involved in translocations were $8 \mathrm{q} 24.1$ and 13q14 (3 cases), 8q24.1 and 11q13 (3), 11q13 and $17 \mathrm{q} 11.2$ (2), and 18q11.2 and 20q11.2 (2). The MYC and CCND1 genes were found to be amplified forming homogeneously staining regions (HSRs) (Yamashita et al., 2005).

Ghadimi et al. (2000) compared the cytogenetic profiles of mismatch-repair-deficient diploid versus mismatch-repair-proficient aneuploid colorectal carcinoma cell lines. Aneuploid carcinomas revealed an average of 19 chromosomal imbalances per cell line and the occurrence of centrosome amplifications. All diploid tumors contained normal centrosomes and only a few chromosome aberrations. Similar studies were performed with comparable results (Abdel-Rahman et al., 2001; Melcher et al., 2002; Mohr and Illmer, 2005). Surprisingly, a near-diploid MMR-proficient cell line (HCA7) revealed multiple reciprocal translocations thus defining a third group of colorectal tumors (AbdelRahman et al., 2001). The colon carcinoma cell lines SW480 and SW620 were derived from different tumor stages of the same patient. Abnormalities found exclusively in SW620 cells (gains of 5 pter $\rightarrow 5 \mathrm{q} 11,12 \mathrm{q} 12 \rightarrow \mathrm{q} 23,15 \mathrm{p} 13 \rightarrow \mathrm{p} 11$, and $16 \mathrm{q} 21 \rightarrow \mathrm{q} 24$ and losses of $2 \mathrm{pter} \rightarrow \mathrm{p} 24,4 \mathrm{q} 28 \rightarrow \mathrm{qter}$, and $6 \mathrm{q} 25 \rightarrow \mathrm{qter}$ ) were viewed as changes that occurred in putative metastatic founder cells (Melcher et al., 2002). In contrast, a cell line established from a colon adenoma was found to be microsatellite stable and the SKY analysis revealed no chromosomal alterations. Nevertheless, incubation with butyrate resulted in a time- and dose-dependent inhibition of proliferation and in a significant increase in cellular differentiation. Thus colon adenoma cell line GEKI-2 may provide a versatile tool for further exploring the underlying mechanisms of protective and promoting factors in early colon cancerogenesis (Menzel et al., 2004).

Cell lines derived from pancreatic carcinomas were simultaneously studied by CGH and SKY analysis (Ghadimi et al., 1999). Recurring chromosomal gains were detected on chromosome arms 3q, 5p, 7p, 8q, 12p, and 20q. Chromosome losses were mapped to chromosome arms $8 \mathrm{p}, 9 \mathrm{p}, 17 \mathrm{p}$, $18 \mathrm{q}, 19 \mathrm{p}$, and chromosome 21. Unbalanced translocations included most frequently i(5)(p10), del(11)(q23), i(12)(p10), $\mathrm{i}(1)(\mathrm{q} 10)$, del(7)(q22) and del(10)(p11) (Sirivatanauksorn et al., 2001). The comparison with CGH data from primary pancreatic tumors indicated that a specific pattern of chromosomal copy number changes was maintained in cell culture. Copy number increases on chromosome $20 \mathrm{q}$ were validated with a probe specific for the nuclear receptor coactivator NCOA3 that maps to chromosome $20 \mathrm{q} 12$ and correlated with increased expression (Ghadimi et al., 1999). Molecular events involved in pancreatic cancer also include mutations in the dominant oncogene KRAS and the tumor suppressor genes TP53, CDKN2A and SMAD4 (Sirivatanauksorn et al., 2001).

Numerous genomic imbalances characteristic of stage IV clear cell renal cell carcinoma (CCRCC) were studied by analyzing ten cell lines established from primary renal tumors. The mutational status of VHL (3p25) and MET (7q31), genes implicated in renal carcinogenesis, were determined for each case. All cases with VHL inactivation had loss of chromosome arm $3 p$ and gain of chromosome arm $5 q$ related primarily to unbalanced translocations, no balanced translocations were noted. Gains of chromosome 7 were not associated with mutations of MET. Specific chromosomal alterations that were previously related to a poor clinical outcome were also found in these lines derived from patients with metastatic disease: losses at 8p, 9p, and 14, and gains of 10 and 17 (Pavlovich et al., 2003).

Metaphase chromosomes obtained from 24 short-term cultured transitional cell bladder carcinomas and five bladder carcinoma cell lines showed specific chromosomal gains and losses, but no recurrent translocation. The application of SKY and FISH techniques improved the karyotype descriptions by identifying 32 additional numerical changes, by establishing the chromosomal origin of 27 markers and two ring chromosomes, by redefining 53 aberrations and by detecting 15 hidden chromosomal rearrangements. Early changes in superficial tumors were found to include regional losses of chromosomes 8, 9 and 11 and gains of the long arms of chromosomes 1 and 18 . More aggressive tumor phenotypes were characterized by losses of the short arms of chromosomes 4 and 17 and the formation of an isochromosome 5p (Fadl-Elmula et al., 2001). A model for bladder cancer progression (cell lines T24 and T24T) was studied by SKY and CGH analysis and positional expression profiling (PEP) (Harding et al., 2002). Chromosomes 8, 12, and X showed similar results for all three methods, whereas a region on the long arm of chromosome 10, gained in T24T compared with T24, was not associated with changes in gene expression. In addition, a candidate gene (RhoGDI2) that may be responsible for the invasive phenotype was identified on chromosome $12 p$ (Harding et al., 2002).

Numerous unbalanced translocations but also reciprocal translocations, isochromosomes and deletions were identified in cell lines and primary tumors derived from patients with high-grade serous adenocarcinoma of the ovary (Rao et al., 2002). Recurring breakpoint clusters were mapped at chromosomal bands 1p36, 2p11, 2p23, 3p21, 3q21, 4p11, 6q11, 8p11, 9q34, 10p11, 11p11, 11q13, 12p13, 12q13, 17q21, 18p11, 18q11, 20q11, and 21q22. Recurrent interstitial deletions of chromosome bands 8p11,11p11, and 12q13 and a recurrent unbalanced translocation $\operatorname{der}(6) \mathrm{t}(6 ; 8)(\mathrm{q} 11 ; \mathrm{q} 11)$ were also detected. In addition, an HSR localized to chromosome band 11q13 was found using SKY to be derived 
from chromosome 12. Subsequent CGH studies revealed the origin of the amplified DNA sequences from chromosome region 12p11.2 (Rao et al., 2002). Furthermore, SKY analysis was applied to characterize cells derived from low and high passage numbers of an ovarian carcinoma cell line. Several specific aberrations were shared between the two cell lines whereas others were unique. Upon prolonged passage in tissue culture the cells developed resistance against flavopiridol, the first inhibitor of cyclin-dependent kinases to enter clinical trials. It is feasible that the observed genetic changes underlie the acquisition of drug resistance (Bible et al., 2000).

Breast cancer cell lines have been widely used as models in functional and therapeutical studies. Kytola et al. (2000) characterized 15 human breast carcinoma cell lines (BT474, BT-549, CAMA-1, DU4475, MCF7, MDA-MB-134, MDA-MB-157, MDA-MB-361, MDA-MB-436, MPE600, SK-BR-3, T-47D, UACC-812, UACC-893, and ZR-75-1) by $\mathrm{CGH}$ and SKY analysis. A multitude of mostly unbalanced structural and numerical chromosomal aberrations was identified with simple translocations, typically consisting of entire translocated chromosome arms, being the most common structural aberrations. Complex marker chromosomes included material from up to seven different chromosomes. Translocations $\mathrm{t}(8 ; 11), \mathrm{t}(12 ; 16), \mathrm{t}(1 ; 16)$, and $\mathrm{t}(15$; 17) were frequently found, although the resulting derivative chromosomes and their breakpoints were strikingly dissimilar (Kytola et al., 2000). There is still only limited knowledge on the order of appearance of different types of genetic aberrations in breast cancer. Rennstam et al. (2001) studied the ERBB2 (Her-2/neu) and CCND1 (cyclin D1) oncogene amplification in flow cytometrically sorted diploid and nondiploid tumor cell populations. The results indicated that ploidy shift, i.e., aneuploidization, in breast cancer is a late genetic event, which is preceded by both oncogene amplifications as well as many chromosomal rearrangements.

Cancer of the uterine cervix $(\mathrm{CaCx})$ is often associated with infection of the patient with high-risk HPVs, however, additional genetic changes are required for tumor progression. Cottage et al. (2001) found a translocation of chromosome 10 or an isochromosome $\mathrm{i}(10 \mathrm{q})$ in immortalised keratinocytes and established $\mathrm{CaCx}$ cell lines suggesting that genes on chromosome 10 are important in HPV mediated immortalisation in vitro. Harris et al. (2003) studied widely used cervical cancer (CC) cell lines. Several recurrent structural chromosomal rearrangements, including $\operatorname{der}(5) \mathrm{t}(5 ; 8)$ (p13;q23) and i(5)(p10); deletions affecting chromosome bands $2 \mathrm{q} 33 \rightarrow \mathrm{q} 36,5 \mathrm{p} 11,5 \mathrm{q} 11$, and 11q23; and breakpoint clusters at 2q31, 3p10, 3q25, 5p13, 5q11, 7q11.2, 7q22, 8p11.2, 8q11.2, 10p11.2, 11p11.2, 14q10, 15q10, 18q21, and 22q11.2 were identified by SKY analysis. Further characterization of genes in the breakpoint clusters may provide clues for understanding the biology and clinical behavior of CC (Harris et al., 2003).

Human prostate cancer cell lines, such as LNCaP, PC-3, DU145, 22Rv1, CWR-R1, DuCaP, LAPC-4, MDA PCa 1, MDA PCa 2a, MDA PCa 2b, PC-346C, PSK-1, and VCaP were studied by SKY (Pan et al., 1999; van Bokhoven et al, 2003). Chromosome abnormalities were identified in all cell lines, although the number and complexity varied greatly among them. PC-346C, established from a primary tumor, exhibited only three clonal structural abnormalities, while DuCaP, established from a metastasis of a patient with a hormone-refractory tumor, exhibited a high number (31) and complex structural abnormalities. Breakpoints were identified in chromosomal regions (e.g., 1, 2, 4, 6, 8p, 10q, $13 \mathrm{q}, 15$, and $16 \mathrm{q}$ ) that were previously described as being involved in prostate cancer.

In solid tumors recurrent reciprocal translocations have only rarely been reported. Tumor heterogeneity and numerous complex clonal and non-clonal aberrations per cell as well as difficulties in obtaining metaphase chromosomes from fresh tumor material have restricted the success of defining tumor specific translocation breakpoints followed by gene identification. Nevertheless, copy number changes and breakpoint cluster of chromosome regions were correlated with tumor stages and other clinical and biological findings and their identification in primary tumors using interphase cytogenetics will thus support prognostication. SKY analysis will always be helpful to determine structural aberrations and complement Array-CGH and expression studies to further the elucidation of the processes leading to tumorigenesis and tumor progression and to prepare for better therapeutic strategies.

\section{SKY analysis of neuroepithelial tumors}

In addition to MYCN amplification and chromosome 1 short-arm deletions/translocations detected by conventional cytogenetics in neuroblastomas (NBLs), molecular cytogenetic studies of advanced-stage NBLs disclosed a high prevalence of gains of the long arm of chromosome 17 in the context of complex karyotypes (more than three changes per metaphase) including complex unbalanced rearrangements. A strikingly high prevalence of the unbalanced translocation $\operatorname{der}(11) \mathrm{t}(11 ; 17)$, leading to concomitant $11 \mathrm{q}$ loss and $17 \mathrm{q}$ gain, delineated a distinct cytogenetic group, not having $1 \mathrm{p}$ deletion and/or MYCN amplification, but additional changes in chromosomes 3 and 7q. In contrast, the $17 q$ translocations with partners other than 11q were associated with $1 \mathrm{p}$ deletion and/or MYCN amplification (Stark et al., 2002). Chromosome aberrations of NBL were later on grouped into early (aberrations involving chromosomes X, 1,3 and 19) or late (involving chromosomes 9, 13, 15, 18, 20, and 21) karyotypic events. However, the gain of the long arm of chromosome 17 that was detected in $80 \%$ of the tumors could not be related to the time of occurrence (Betts et al., 2005). NBL cell sublines resistant to vincristine (VCR) and doxorubicin (DOX) were established by Kotchetkov et al. (2003). The development of drug resistance and acquisition of certain karyotypic alterations is associated with an increase of additional malignant properties that may contribute to the poor prognosis in advanced forms of NBL.

The molecular cytogenetic analysis of the neuroglioma cell line H4 (NBL) revealed a monoclonal and near triploid genotype with 24 structural aberrations. The generation of 
transcription factors by fusion proteins might be the reason for impaired mRNA expression of the LGI1 candidate tumor-suppressor gene (Krex et al., 2001). In glioblastomas, Kubota et al. (2001) identified recurrent marker chromosomes, e.g. t $(4 ; 16)(\mathrm{q} 21 ; \mathrm{q} 23)$, and amplifications of chromosomal bands such as 4q12, 16q13 and others. Interestingly, amplified segments were often found to be translocated or inserted, and low-level amplifications prevailed.

A so far unknown unbalanced translocation der(17)t(7; 17)(?;q?) was identified in uveal melanoma cell lines and primary uveal melanomas (Naus et al., 2001). Additionally, abnormalities involving chromosome 6 or 8 were found to be twice as common as observed with cytogenetic analysis.

\section{Chromosome aberrations detected in familial tumors}

Searching for genetic biomarkers in HNSCCs indicated that the loss of chromosomes 17 and 22 might be associated with a family history of cancer (Bergamo et al., 2005).

Looking for constitutional chromosome translocations in order to identify susceptibility genes in familial urothelial cell carcinomas (UCC) Aben et al. (2001) performed routine chromosome banding and SKY analysis, however, no aberrations were detected.

Members of a Japanese family were found to be afflicted with late onset CCRCC (RCC, 4 patients), gastric cancer (one patient) and exocrine pancreatic cancer (one patient). A germline translocation $\mathrm{t}(1 ; 3)(\mathrm{q} 32 ; \mathrm{q} 13.3)$ was identified in five members of the family including all three RCC cases tested. Identification of the genes residing at the breakpoints and VHL mutations will help to explain the familial occurrence of these tumors (Kanayama et al., 2001). In an attempt to define the cytogenetic aberrations from early tumors to late RCC, Phillips et al. (2001) studied 23 renal tumors harvested from six unrelated VHL patients. Cysts and low-grade solid lesions were near-diploid and contained 1-2 reciprocal translocations, dicentric chromosomes, and/or isochromosomes. In contrast, a high-grade lesion and its nodal metastasis were found to be aneuploid. These findings also illustrated the cytogenetic heterogeneity of different VHL lesions from the same kidney, supporting the multiclonal origins of hereditary RCCs (Phillips et al., 2001).

\section{Studying mouse and rat tumor models with SKY}

Rat and mouse have become important animal models to study human tumorigenesis, tumor progression and to perform functional investigations in vivo. The development of powerful cytogenetic tools such as SKY has allowed for routine karyotyping of mouse and rat chromosomes ( $\mathrm{Li}-$ yanage et al., 1996; Buwe et al., 2003). Several studies underlined that the improved ability to detect chromosome rearrangements using a combination of SKY, CGH and FISH analyses is helpful for a correct study design and detailed interpretation of the results.

Chromosome aberrations of human and mouse acute promyelocytic leukemia (APL) were compared by Le Beau et al. (2002). Expression of the human Pml-Rara comple- mentary DNA initiated the development of leukemia in murine granulocyte precursor cells. Recurring numerical abnormalities included the gain of chromosome 15 in the mouse tumors, which is comparable to the gain of chromosome 8 in human. Thus, these results suggested that PmlRara-initiated murine leukemias are associated with a defined spectrum of genetic changes, and that these secondary mutations recapitulate, in part, the cytogenetic abnormalities found in human APL (Le Beau et al., 2002). The coexpression of a reciprocal form of the fusion, Rara-Pml, increased the likelihood of APL development (55-60\%), but did not shorten latency. The spleen tumor cells from transgenic mice with APL were also studied for evidence of secondary genetic events using SKY analysis. Interstitial or terminal deletions of the distal region of one copy of chromosome 2 (del(2)) were found in one of five tumors expressing Pml-Rara, but in 11 of 13 tumors expressing both Pml-Rara and Rara-Pml $(P<0.05)$. These cells contained additional chromosome changes such as gain of chromosome 15 or losses of chromosomes 11, X or Y or were found to be tetraploid, which may provide an advantage to the transformed cells (Zimonjic et al., 2000). Furthermore, different cooperating events may generate leukemia via different activated cytokine signaling pathways (Le Beau et al., 2003), such as Flt3, Csf2rb1/2 and Il3. Also involved is the increased $M y c$ expression via ras/Mapk activation, Bclxl expression via Stat5 (signal transducer and activator of transcription 5) and Pik3/Akt1 (phosphatidylinositol 3-kinase/v-akt murine thymoma viral oncogene homolog), and $\mathrm{Bcl} 2$ phosphorylation via Mapk1/3 (extracellular signal-related kinase 1/2) or PLC $\gamma$ (phospholipase C- $\gamma$ ). Identifying the genes that drive chromosome gains or losses in human and murine myeloid leukemias may offer insights into the pathogenesis or progression of leukemias and may provide new therapeutic targets (Le Beau et al., 2003).

To study the $\mathrm{v}$-abl/myc-dependent tumorigenesis in mouse B cells, BALB/c PreB lymphocytes were immortalized by $\mathrm{v}$-abl and stably transfected with a conditional MycER vector. A comprehensive analysis using chromosome painting, SKY, FISH and mBANDing revealed a duplication of the E1/E2 bands of chromosome 11. These findings suggest that the Pre-B ABL/MYC cells may be used to analyze the genetic changes affecting chromosome 11 that are associated with $\mathrm{v}$-abl/myc-dependent tumorigenesis in mouse B cells (Benedek et al., 2004).

A mouse model of malignant plasma cell tumor (PCT) development was characterized by the SKY analysis of induced primary BALB/c plasmacytomas for the presence of chromosomal aberrations that took place subsequent to the initiating Myc-activating translocations T(12F1;15D2) or T(6C1;15D2). Recurrent amplifications of chromosome 1 and promiscuous non-reciprocal translocations of chromosome 5 (52\% prevalence) suggested the existence of important PCT progressor genes on bands $1 \mathrm{~B} / \mathrm{C}$ and $5 \mathrm{~F}$ (Coleman et al., 2000). Similar translocations involving chromosome band 5F were detected by Helmrich et al. (2005) in an $\mathrm{E} \mu$-myc lymphoma model with defects of the $C d k n 2 a$ (alias INK4a/ARF) locus. Furthermore, SKY and CGH 


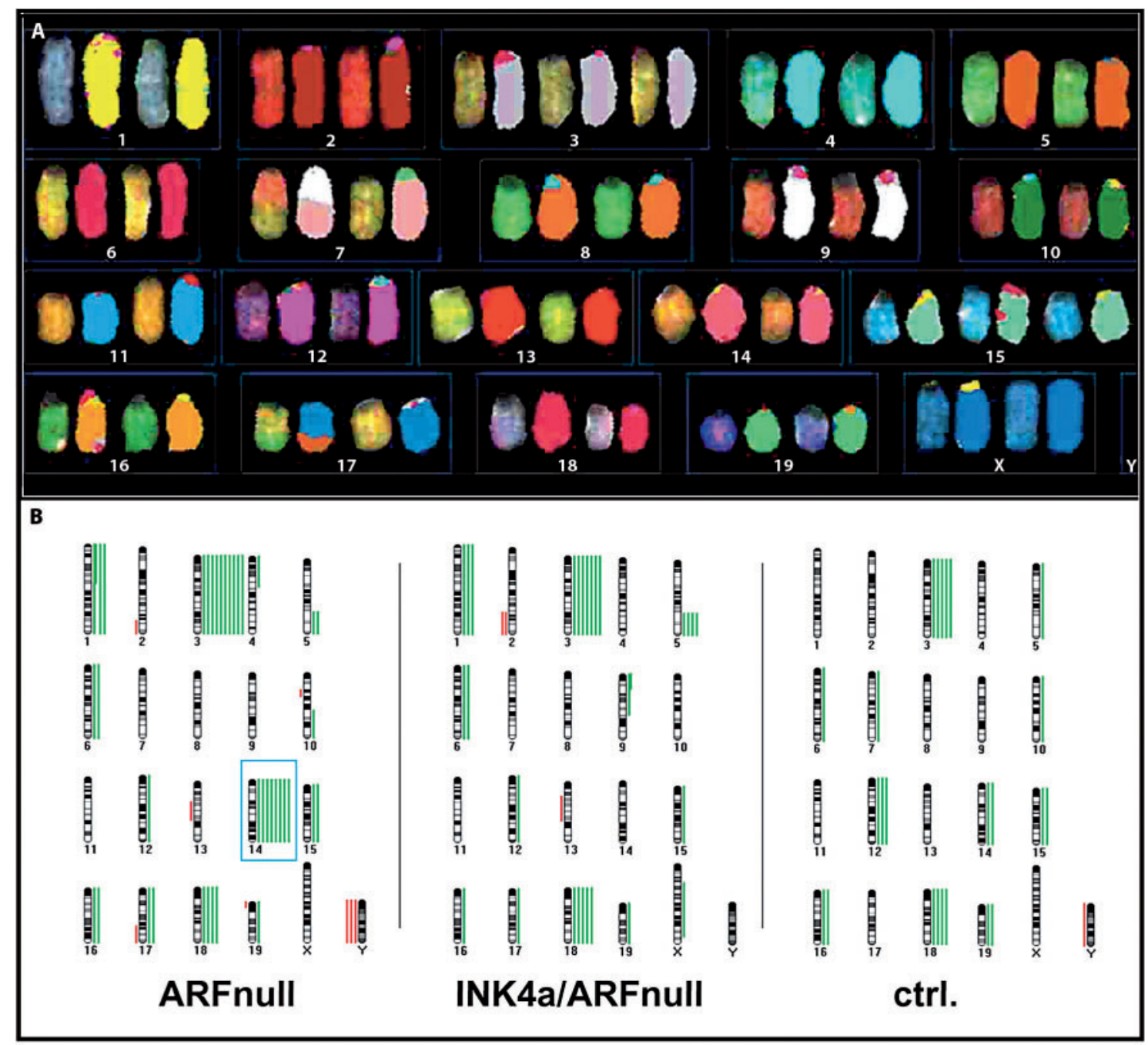

Fig. 4. Cytogenetic characteristics of $A R F$ null and INK4a/ARFnull lymphomas in a $E \mu$-myc transgenic mouse model. (A) Representative SKY data of a primary ARFnull (A10) lymphoma sample. (B) Summarized cytogenetic results based on SKY and CGH analyses (green bars to the right and red bars to the left indicating gains and losses, respectively) of ARFnull $(\mathrm{n}=15)$, INK4a/ARFnull $(\mathrm{n}=17)$ and ctrl. lymphomas $(\mathrm{n}=6)$. Note that no chromosome 14 gain has been detected in INK4a/ARFnull samples, although this alteration is common in ARFnull and ctrl. lymphomas (Helmrich et al., 2005). Reprinted from Helmrich et al. (2005) with permission from Nature Publishing Group.

analysis allowed for predicting responsiveness to anticancer therapy based on molecular findings at diagnosis. The gain of chromosome 14 , which was never detected in INK4a/ARFnull lymphomas, defined an ARFnull subgroup with superior treatment outcome. Gain of chromosome 6 was identified as a recurrent chromosomal aberration that predisposed $A R F$ null tumors to their subsequent INK4a loss during therapy (Fig. 4). These data illustrated how cytogenetic information from cancer specimens might complement established prognostic markers and may improve anticancer treatment strategies (Helmrich et al., 2005).

The DCPC21 plasmacytoma belongs to a small group of plasmacytomas that are unusual in that they appear to be translocation-negative. DCPC21 harbors $M y c$ and Igh genes on extrachromosomal elements (EEs) from which $M y c$ is transcribed, as shown by $M y c$ mRNA tracks and extrachromosomal gene transfer experiments. The transcriptional activity of these EEs is further supported by the presence of the transcription-associated phosphorylation of histone $\mathrm{H} 3$ (H3P) on the EEs. Thus, Myc expression is achieved by an alternative mechanism outside the chromosomal locations of the $M y c$ gene. Therefore, other 'translocation-negative' experimental and human tumors with fusion transcripts or oncogenic activation may indeed carry translocation(s), however, in an extrachromosomal form (Wiener et al., 1999).

Tumors which arose from hyperplastic ductal and lobular mammary lesions in a transgenic mouse model expressing the $M y c$ gene under the MMTV \pm LTR promoter 
showed high rates of apoptosis and of chromosomal instability. Normal Trp53 was strongly expressed in premalignant mammary glands and in mammary tumors derived from the MMTV-Myc strain. When the MMTV-Myc strain was mated to a Trp53-deficient strain, a lack of both Trp53 alleles in the presence of $M y c$ overexpression resulted in a dramatic hyerplastic alteration in mammary gland development. In contrast, only mild ductal and lobular hyperplasias were seen in MMTV-Myc mice that contained both Trp53 alleles (MMTV-Myc/Trp53+/+); an intermediate phenotype occurred in mice with a single intact (MMTV-Myc/ Trp53+/-) Trp53 allele. A detailed chromosomal analysis of the developing mammary carcinomas using SKY revealed that there were multiple chromosomal alterations in the $M y c$-overexpressing cells that contained either one or two unmutated $\operatorname{Trp} 53$ alleles. Variable ploidy changes, a common translocation of chromosome 11, and other chromosomal aberrations were observed. These data thus support an interaction between Myc and Trp53 in mammary development, but suggest that loss of Trp53 is required neither for $M y c$-dependent tumorigenesis nor for $M y c$-dependent chromosomal instability. The comparison of the patterns of chromosomal aberrations with human breast cancers showed similarities in several syntenic regions (McCormack et al., 1998; Weaver et al., 1999).

Germline mutations of the Brcal gene are responsible for most cases of familial breast and ovarian cancers, but somatic mutations are rarely detected in sporadic events. The fact that Brcal is responsible for the integrity of the genome was demonstrated by Shen et al. (1998). Murine embryos carrying a Brcal null mutation were found to be developmentally retarded and hypersensitive to $\gamma$-irradiation, suggesting a failure in DNA damage repair. This notion was supported by SKY analysis of metaphase chromosomes, which displayed numerical and structural aberrations. Excision of exon 11 of Brcal in the mouse, using a conditional knockout (Cre-loxP) approach, resulted in mammary tumor formation after long latency. All tumors exhibited chromosome instability, yet they displayed a pattern of chromosomal gain and loss that was similar to the pattern in human breast carcinomas. The distal region of chromosome 11 , which is syntenic to human chromosome $17 \mathrm{q} 11 \rightarrow$ qter, the mapping position of $E R B B 2$ was found to be gained. The proximal region of chromosome 11 (11A-B), which is orthologous to the short arm of human chromosome 17 was lost. Based on additional information the authors concluded that the pattern of genomic imbalances is conserved between BRCA1-associated mammary gland tumors in mice and humans (Weaver et al., 2002).

The conditional expression of the activated Erbb2 gene under its endogenous promoter in the mammary epithelium of the mouse resulted in accelerated lobular development and focal mammary tumors. Short-term cultures of primary tumors revealed the amplification of the Erbb2 gene in correlation with a loss on mouse chromosome 4 involving bands $\mathrm{D}-\mathrm{E}$, a region that is orthologous to distal human chromosome 1p. This region may harbour putative tumor suppressor genes that are of importance for the tu- mor formation in this model of human breast cancer (Montagna et al., 2002). Another breast cancer model based on the expression of polyomavirus middle $\mathrm{T}$ antigen under the control of the mouse mammary tumor virus promoter in transgenic mice showed the induction of aggressive mammary gland adenocarcinomas at an early age. A combined chromosome analysis and gene expression study revealed a consistently increased expression of septin 9 (Sept9). The family of septin genes is involved in a plethora of cellular processes, including cytokinesis in yeast and vesicle transport, and possesses GTPase activity. These results suggested that signaling via members of the septin family plays a novel and common role in breast tumorigenesis (Montagna et al., 2003).

Annexin 7 (ANXA7) acts as a tumor suppressor gene in prostate cancer, where loss of heterozygosity and reduction of ANXA7 protein expression is associated with aggressive metastatic tumors. Srivastava et al. (2003) developed an Anxa7 ${ }^{+/-}$knockout mouse that showed a cancer-prone phenotype. Genome array analysis of HCC tissue indicated that the $A n x a 7^{+/}$genotype was accompanied by profound reductions of expression of several other tumor suppressor genes, DNA repair genes, and apoptosis-related genes. The authors concluded that haploinsufficiency of Anxa7 expression appears to drive disease progression to cancer because of genomic instability through a discrete signaling pathway involving other tumor suppressor genes, DNA repair genes, and apoptosis-related genes (Srivastava et al., 2003). DMINs and HSRs are cytological manifestations of DNA amplification and were not previously found in mouse HCCs and adult human HCCs. Zimonjic et al. (2001) identified DMINs derived from mouse chromosome 19. The recognition of these loci could lead to the cloning of new genes or identification of known genes important in development or progression of HCC.

Early passage mouse cell lines of lung adenocarcinomas were studied using the SKY technology by Sargent et al. (2002). Gains and losses of entire chromosomes and recurrent translocations were identified. The minimal regions of chromosomal alteration, $1 \mathrm{G} 1,2 \mathrm{~F} 1,4 \mathrm{C} 4,6 \mathrm{D}, 7 \mathrm{~F} 1,8 \mathrm{~B} 3$, and $12 \mathrm{C} 2$, contain putative susceptibility genes for mouse lung adenocarcinoma. Similar linkage groups are altered in human lung adenocarcinoma, implying that this mouse is a valid genetic model for the study of human lung adenocarcinoma susceptibility (Sargent et al., 2002). Novel candidate genes for the progression of lung cancer related to systemic metastases and to a poor prognosis were identified by analyzing parental and modified NCI-H460 cells (H460SM) after endobronchial implantation into a nude rat (Liu et al., 2004). SKY detected a new inversion within $17 \mathrm{q}$ and loss of an extra normal copy of chromosome 14 present in parental NCI-H460 cells. Expression profiling of orthotopic primary tumors revealed the differential expression of 360 genes (Liu et al., 2004).

The widely used azoxymethane (AOM)-induced mouse colon tumor model recapitulates many of the histopathological features associated with the multistage progression of human sporadic colorectal cancers (CRCs). CGH, SKY 
and microsatellite analysis of a cell line derived from these carcinogen-induced tumors revealed a pseudotetraploid karyotype with loss of only the $\mathrm{Y}$ chromosome, thereby providing evidence for the minimal role of CIN. Most primary tumors displayed low-level microsatellite instability (MSIL) and showed a significant expansion to high-level instability (MSI-H) in the AJ02-NM0 cells. Based on their molecular and cytogenetic findings, the authors proposed that carcinogen-induced tumors may develop via mechanisms independent of the 'classical' CIN or MSI pathways (Guda et al., 2004).

Investigations of cell lines established from skin tumors of mice expressing either the E6 or E7 oncoprotein of the HPV type 16 under control of the keratin 14 promoter showed that tumorigenesis via E6 requires copy number increases of mouse chromosome 6 , which is partially orthologous to human chromosome $3 \mathrm{q}$, a region gained in HPVassociated carcinomas (Schaeffer et al., 2004). Pons et al. (2005) studied mouse epidermal carcinogenesis by analyzing a minor epithelial cell subpopulation (CarC-R) contained in the highly malignant spindle carcinoma cell line CarC. Furthermore, several single-cell clones with either stable epithelial or fibroblastic phenotypes were isolated from an explanted CarC-R tumor (CarC-RT). A T(14;15) translocation was present in only a minority $(1.9 \%)$ of CarC$\mathrm{R}$ cells, but was widely spread in CarC-RT and its derived cell clones, regardless of their epithelial or fibroblastic phenotype. These results indicated that the $\mathrm{T}(14 ; 15)$ segregated with malignancy (Pons et al., 2005).

Rehen et al. (2001) presented direct evidence for genomic variability, manifested as chromosomal aneuploidy, among developing and mature neurons in the brain of the normal mouse. The analysis of embryonic cerebral cortical neuroblasts in situ revealed lagging chromosomes during mitosis, suggesting the normal generation of aneuploidy in these somatic cells. SKY analysis identified approximately $33 \%$ of neuroblasts as aneuploid, showing either hyperploi$\mathrm{dy}$, monosomy, and/or trisomy. Interphase fluorescence in situ hybridization supported this rate of aneuploidy and detected aneuploidy also in adult neurons (Rehen et al., 2001).

Surprisingly, the study of tumor-associated endothelial cells identified chromosome aberrations and aneuploidy using SKY analysis as well as centrosome anomalies in two independent xenograft mouse models. There was no evidence of human tumor-derived chromosomal material in the mouse tumor endothelial cells (Hida et al., 2004).

An in vivo model system for metastatic prostate cancer was developed by Wang et al. (2005). Pieces of prostate cancer tissue from a patient were grafted in testosterone-supplemented male NOD-SCID mice at the subrenal capsule graft site permitting high tumor take rates. Subsequently, the tumor tissues were grafted into mouse prostates. Samples of metastatic tissue were regrafted in mouse anterior prostates. SKY analysis showed few chromosomal alterations in the PCal-met subline. Thus, orthotopic xenografts of the transplantable tumor lines and metastatic sublines could be used for studying various aspects of metastatic prostate cancer, including metastasis to bone (Wang et al., 2005).

Research on meiotic chromosome segregation was performed on mouse oocytes (Hodges et al., 2002). Mutations that affect oocyte growth were found to increase the frequency of congression failure at first meiotic metaphase. A cause-and-effect relationship was suggested because the increased congression failure was correlated with meiotic non-disjunction. These results implicated that it may be possible to develop prophylactic treatments for reducing the risk of age-related aneuploidy (Hodges et al., 2002). Furthermore, a mouse sertoli cell line was characterized by SKY, because it provides an ideal system for the in vitro analysis of function and responsiveness to biochemical/ hormonal factors (Guttenbach et al., 2001).

\section{Studying mechanisms of tumorigenesis}

Mouse models and human and mouse cell lines are frequently used to study not only a specific disease but also gene pathways and gene functions.

The diverse group of cancer cell lines established by the National Cancer Institute for the purpose of anticancer drug discovery was analyzed using SKY analysis (Roschke et al., 2003). Along with the karyotypic description of the cell lines the authors defined and studied karyotypic complexity and heterogeneity (metaphase-to-metaphase variations) based on three separate components of genomic anatomy: (a) ploidy, (b) numerical changes, and (c) structural rearrangements. A striking lability of centromeric regions distinguished the epithelial tumor cell lines. Balanced translocations were as frequent in absolute number within the cell lines derived from solid as from hematopoietic tumors. Important similarities were noticed between karyotype changes in cancer cell lines and those seen in primary tumors. This dataset offers insights into the causes and consequences of the destabilizing events and chromosomal instability that may occur during tumor development and progression. It also provides a foundation for investigating associations between structural genome anatomy and cancer molecular markers and targets, gene expression, gene dosage, and resistance or sensitivity to tens of thousands of molecular compounds (Roschke et al., 2003).

The function of the MYC gene as part of the DNA repair mechanisms was reported for the first time by Karlsson et al. (2003). The overexpression of MYC disrupted the repair of double-strand DNA breaks, resulting in a several-magnitude increase in chromosomal breaks and translocations.

Telomeres are known to play crucial roles in protecting the integrity of eukaryotic chromosomes and maintaining genomic stability of human cells. Telomere lengths of individual chromosomes in normal human somatic cells are heterogeneous and undergo progressive shortening during aging. When applying SKY analysis and sequential telomere quantitative fluorescence in situ hybridization on metaphases obtained from ovarian and esophageal epithelial cells, Deng et al. (2004) detected a correlation between the 
distribution of critically short telomeres and the occurrence of specific chromosomal structural aberrations. Hao and Greider (2004) established mouse embryonic fibroblast (MEF) lines from late generation $\mathrm{mTR}^{-/-}$and wild-type animals. In early passages, $\mathrm{mTR}^{-/-} \mathrm{G} 6$ cell lines showed more chromosome ends with no telomere signal, more chromosome end-to-end fusions and greater radiosensitivity than wild-type lines. At later passages wild-type MEF lines revealed a similar or higher rate of genomic instability than $\mathrm{mTR}^{-/}$cells. Both post-crisis mTR ${ }^{-/-}$G6 MEFs and wildtype MEFs showed loss of Trp53 and $\gamma$-H2afx phosphorylation in response to irradiation, indicating a loss of DNA damage checkpoints (Hao and Greider, 2004). Qi et al. (2005) described a new mechanism by which short telomeres inhibit tumorigenesis through interference with oncogenic translocations. They proposed that telomere fusion to DNA double strand breaks competes with the generation of oncogenic translocations and thus reduces tumor formation. The conclusion was drawn based on studies in mice that are null for both ataxiatelangiectasia-mutated (Atm) and telomerase RNA (mTR). The first generation (G1) $\mathrm{Atm}^{-1-} \mathrm{mTR}^{-/-}$mice showed a lower rate of tumor formation than $\mathrm{Atm}^{-/-} \mathrm{mTR}^{+/+}$mice. Translocations of the T-cell receptors on chromosome 14, which initiate tumorigenesis, were interrupted by fusion with telomeres and telomere repeats were also detected at the translocation junctions in pre-malignant thymocytes (Qi et al., 2005). Reversal of telomere shortening by the forced expression of telomerase in normal cells has been shown to elongate telomeres and extend the replicative life span. Extension of the life span as a consequence of the functional inactivation of Trp53 is frequently associated with loss of genomic stability. Analysis of telomerase induced extended-life-span fibroblast (TIELF) cells by G-banding and SKY detected the transient formation of aberrant structures, which were subsequently resolved in higher passages. However, the Trp53-dependent G1 checkpoint was intact as assessed by functional activation of Trp53 protein in response to ionizing radiation and subsequent Trp53-mediated induction of p21Waf1/Cip1/ Sdi1. TIELF cells were not tumorigenic and had a normal DNA strand break rejoining activity and normal radiosensitivity in response to ionizing radiation (Pan et al., 1999; Vaziri et al., 1999).

DNA repair mechanisms after DNA double-strand breaks are very intriguing and general processes in life. $\mathrm{Xrcc} 2$ is a protein with homology to Rad51, the core component of homologous recombination (HR), and with a non-redundant role in damage repair. High levels of chromosomal alterations and reduced SCE-rates were found in primary or immortal $\mathrm{Xrcc}^{-/-}$embryonic fibroblasts by Deans et al. (2003), which may be comparable to the disruption of breast cancer-predisposing (Brca) genes. Several components of the nonhomologous DNA endjoining (NHEJ) pathway in the maintenance of genomic stability in mouse embryonic fibroblasts (MEFs) were assessed by Ferguson et al. (2000). MEFs homozygous for mutations that inactivate either DNA ligase IV (Lig4) or Ku70 displayed dramatic genomic instability. The aberrant events ranged from chromosomal fragmentation to nonreciprocal complex translocations. The authors concluded that NEHJ plays a crucial role as a caretaker of the mammalian genome, and that an alternative repair pathway exists that often leads to nonreciprocal translocations (Ferguson et al., 2000).

Poly(ADP-ribose) polymerase (PARP)-1, a detector of single-strand breaks, plays a key role in the cellular response to DNA damage. It was suggested that Parp1-deficient mice have a severe telomeric dysfunction leading to telomere shortening and increased end-to-end fusions. Using QFISH and SKY analyses Samper et al. (2001) showed that primary Parp1 ${ }^{-/}$cells showed a frequency of only two endto-end fusions per 100 metaphases, much lower than that described previously.

The extent of chromosome instability induced in cultured human colon carcinoma HCT116 cells by the antitumor radiomimetic enediyne antibiotic C-1027 was examined using SKY (McHugh et al., 2005). Chromosome misrejoining was associated to a much greater extent with C-1027-induced than with ionizing radiation-induced cell growth inhibition. The extreme cytotoxicity of C-1027 may reflect both induction and erroneous repair of DNA doublestrand breaks in the whole genome and/or in subgenomic targets such as telomere sequences.

Radiation-induced neoplastic transformation of human epithelial cells was studied by cytogenetic analysis of the human thyroid epithelial cell line HTori-3. The exposure of the cell line to different doses of $\alpha$ - and $\gamma$-irradiation led to subsequent tumor formation in athymic nude mice. Chromosome abnormalities were determined in the parental line HTori-3 and in nine different HTori lines established from the developed tumors. Several chromosomal aberrations were found to be characteristic for simian virus 40 immortalization and/or radiation-induced transformation of human thyroid epithelial cells. In contrast, deletions on chromosomes $9 \mathrm{q} 32 \rightarrow \mathrm{q} 34$ and $7 \mathrm{q} 21 \rightarrow \mathrm{q} 31$ as well as increased copy numbers of chromosome 20 were identified as cytogenetic markers important for the tumorigenic process (Zitzelsberger et al., 2001).

Antisense and ribozyme-mediated temporary inhibition of $B U B 1$ was used to study the consequences of mitotic checkpoint failure on the development of aneuploidy. The analysis of cell colonies selected by soft agar growth showed evidence of chromosome instability and delayed senescence, without being tumorigenic in nude mice. These data suggested that chromosomal instability and aneuploidy are early changes that precede tumorigenicity in the multistep process leading to neoplastic transformation (Musio et al., 2003).

Mapping of artifical transgene insertion sites in mouse chromosomes was facilitated by the sequential application of SKY and FISH analysis as demonstrated by Matsui et al. (2002). A renin/green fluorescent protein (GFP) fusion gene construct (Ren-GFP) was found to be integrated in the transgenic mouse, $\operatorname{Tg}($ Ren-GFP) $1 \mathrm{Kwg}$, into a single chromosomal site of chromosome 4 at A2-3. Generating transgenic mouse models using large transgenes led to the observation that more than 40 copies of a specific transgene 
(bEMS4) were stably incorporated in a single insertion site at the breakpoint of a BAC-mediated chromosome translocation T(3;9) (Abrahams et al., 2003). Hardt et al. (1999) developed an in situ technique to label individual euchromatic chromosome arms in interspecific crosses between Mus musculus (MMU) and M. spretus (MSP). Comparative hybridization of MMU versus MSP DNA and subsequent spectral analysis of the euchromatic hybridization profiles discriminated between maternal (MMU) and paternal (MSP) chromosomes in F1 hybrids. This allowed for the visualization of recombination events in back crosses of the two mouse species and, thus, could be used as an adjunct technique in genetic mapping studies (Hardt et al., 1999).

Another goal of the development of mouse models is the implementation and testing of cancer gene therapy. Transfer and expression of suicide genes is considered as a proactive tool to enhance the safety of somatic transgenesis. Frank et al. (2004) used retroviral vectors encoding the thymidine kinase gene of herpes simplex virus and transduced EL-4 lymphoma cells. The induced experimental tumors in congeneic $\mathrm{C} 57 \mathrm{Bl} / 6$ mice were treated with ganciclovir (GCV) resulting in tumor remission. GCV-resistant relapses occurred and were found to be associated with either epigenetic transgene silencing, escape by postinsertional recombination or the complete loss of the retrovirally marked fusion chromosome, which was confirmed by SKY analysis. Considering the mechanisms of escape, the proactive use of suicide genes to prevent complications of insertional mutagenesis may still be efficient (Frank et al., 2004). In addition, leukemic complications in mice after highcopy retroviral gene transfer of the multidrug resistance 1 (Abcb1) cDNA were reported. SKY demonstrated additional chromosomal translocations in a subset of cases, indicative of secondary genetic instability. Also, insertional mutants may be amplified in vitro prior to transplantation. On the basis of these findings, the authors suggested the use of preclinical doseescalation studies to define a therapeutic index for retroviral transgene delivery (Modlich et al., 2005).

A large amount of $\mathrm{T}$ cells is required for adoptive immunotherapy in a clinical setting. Therefore, T-cell lifespan extension by human telomerase reverse transcriptase (hTERT) transduction is of particular interest, but constitutive expression of hTERT is associated with malignant transformation. Schreurs et al. (2005) performed an extensive cytogenetic analysis of hTERT transduced MART-1 (melanoma antigen recognized by T cell 1 ) - and human papillomavirus type 16 (HPV16) E7-specific human CD8 ${ }^{+}$cytotoxic T lymphocytes (CTLs). The results showed the development of minor chromosomal aberrations in an hTERT-transduced MART-1-specific CTL clone, whereas severe clonal aberrations were detected in an hTERT-transduced HPV16 E7specific CTL clone. Furthermore, hTERT transduction did not protect CTLs from immunosenescence, because the HPV16 E7-specific, hTERT-transduced CTL clone showed a decreased functional activity on prolonged culture. Therefore, the currently available data suggest that clinical application of hTERT-transduced CTLs should proceed with caution (Schreurs et al., 2005).

\section{Analyzing chromosome evolution}

Comparative mapping data between the Hominidae and Cercopithecidae genomes were supplemented by a study of baboon (Papio hamadryas) metaphase chromosomes using probes derived from human chromosomes. Human (HSA) chromosome 2 was found to be homologous to baboon (PHA) chromosomes 12 (HSA2q) and 13 (HSA2p), whereas three baboon chromosomes corresponded to two different human chromosomes: PHA3 to HSA7 and HSA21, PHA7 to HSA14 and HSA15, and PHA10 to HSA20 and HSA22 (Best et al., 1998).

The baboon and macaque karyotypes appeared to be similar by G-banding studies and SKY analysis. In addition, a SKY karyotype was established from a rheboon, the only long-term survivor of 26 pregnancies resulting from matings between female baboons (Papio hamadryas) and male rhesus macaques (Macaca mulatta). No differences were detected in any of the rheboon's pairs of autosomes, reinforcing the apparent identity of the two parental karyotypes. Nevertheless, a testicular biopsy revealed hypoplasia of the seminiferous tubules with few Leydig cells and large lumena. Thus, the testicular and meiotic findings in the rheboon were similar to those observed in other hybrids, even though the parental karyotypes appear identical (Moore et al., 1999).

\section{Acknowledgements}

We thank Dr. Mario Hermsen, IUOPA Hospital central de Asturias, Bloque Polivalente A, $1^{\circ}$ planta Julián Clavería s/n, Oviedo, Spain, for the longstanding successful and stimulating collaboration. We are grateful for the inspiring cooperation with Prof. Dr. med. Bernd Dörken (Director) and Prof. Dr. med. Clemens Schmitt, Charité - Universitätsmedizin Berlin, Campus Virchow - Klinikum, Medizinische Klinik mit Schwerpunkt Hämatologie und Onkologie, Berlin, Germany. We appreciate the ongoing support of Applied Spectral Imaging $\mathrm{GmbH}$, Edingen, Germany and Applied Spectral Imaging, Ltd., Migdal Ha'Emek, Israel. We acknowledge the support of Leica Microsystems, Wetzlar and Mannheim, Germany. 


\section{References}

Abdel-Rahman WM, Katsura K, Rens W, Gorman PA, Sheer D, Bicknell D, Bodmer WF, Arends MJ, Wyllie AH, Edwards PA: Spectral karyotyping suggests additional subsets of colorectal cancers characterized by pattern of chromosome rearrangement. Proc Natl Acad Sci USA 98:2538-2543 (2001).

Aben KK, Macville MV, Smeets DF, Schoenberg MP, Witjes JA, Kiemeney LA: Absence of karyotype abnormalities in patients with familial urothelial cell carcinoma. Urology 57:266-269 (2001)

Abrahams BS, Chong AC, Nisha M, Milette D, Brewster DA, Berry ML, Muratkhodjaev F, Mai S, Rajcan-Separovic E, Simpson EM: Metaphase FISHing of transgenic mice recommended: FISH and SKY define BAC-mediated balanced translocation. Genesis 36:134-141 (2003).

Adam P, Katzenberger T, Seeberger H, Gattenlohner S, Wolf J, Steinlein C, Schmid M, MullerHermelink HK, Ott G: A case of a diffuse large B-cell lymphoma of plasmablastic type associated with the $t(2 ; 5)(\mathrm{p} 23 ; \mathrm{q} 35)$ chromosome translocation. Am J Surg Pathol 27:1473-1476 (2003).

Akervall J, Guo X, Qian CN, Schoumans J, Leeser B, Kort E, Cole A, Resau J, et al: Genetic and expression profiles of squamous cell carcinoma of the head and neck correlate with cisplatin sensitivity and resistance in cell lines and patients. Clin Cancer Res 10:8204-8213 (2004).

Allen RJ, Smith SD, Moldwin RL, Lu MM, Giordano L, Vignon C, Suto Y, Harden A, et al: Establishment and characterization of a megakaryoblast cell line with amplification of MLL. Leukemia 12:1119-1127 (1998).

Amini RM, Berglund M, Rosenquist R, Von Heideman A, Lagercrantz S, Thunberg U, Bergh J, Sundstrom C, et al: A novel B-cell line (U-2932) established from a patient with diffuse large Bcell lymphoma following Hodgkin lymphoma. Leuk Lymphoma 43:2179-2189 (2002).

Anderlid BM, Schoumans J, Anneren G, Sahlen S, Kyllerman M, Vujic M, Hagberg B, Blennow E, Nordenskjold M: Subtelomeric rearrangements detected in patients with idiopathic mental retardation. Am J Med Genet 107:275-284 (2002).

Andersson J, Sjogren H, Meis-Kindblom JM, Stenman G, Aman P, Kindblom LG: The complexity of KIT gene mutations and chromosome rearrangements and their clinical correlation in gastrointestinal stromal (pacemaker cell) tumors. Am J Pathol 160:15-22 (2002)

Astrom A, D'Amore ES, Sainati L, Panarello C, Morerio C, Mark J, Stenman G: Evidence of involvement of the PLAG1 gene in lipoblastomas. Int J Oncol 16:1107-1110 (2000).

Barnard M, Bayani J, Grant R, Teshima I, Thorner P, Squire J: Use of multicolor spectral karyotyping in genetic analysis of pleuropulmonary blastoma. Pediatr Dev Pathol 3:479-486 (2000).

Bayani J, Squire JA: Advances in the detection of chromosomal aberrations using spectral karyotyping. Clin Genet 59:65-73 (2001)

Bayani JM, Squire JA: Applications of SKY in cancer cytogenetics. Cancer Invest 20:373-386 (2002).

Bayani J, Zielenska M, Pandita A, Al-Romaih K, Karaskova J, Harrison K, Bridge JA, Sorensen P, et al: Spectral karyotyping identifies recurrent complex rearrangements of chromosomes 8,17 , and 20 in osteosarcomas. Genes Chromosomes Cancer 36:7-16 (2003).
Benedek K, Chudoba I, Klein G, Wiener F, Mai S: Rearrangements of the telomeric region of mouse chromosome 11 in Pre-B ABL/MYC cells revealed by mBANDing, spectral karyotyping, and fluorescence in-situ hybridization with a subtelomeric probe. Chromosome Res 12:777-785 (2004).

Bergamo NA, da Silva Veiga LC, dos Reis PP, Nishimoto IN, Magrin J, Kowalski LP, Squire JA, Rogatto SR: Classic and molecular cytogenetic analyses reveal chromosomal gains and losses correlated with survival in head and neck cancer patients. Clin Cancer Res 11:621-631 (2005).

Best RG, Diamond D, Crawford E, Grass FS, Janish C, Lear TL, Soenksen D, Szalay AA, Moore CM Baboon/human homologies examined by spectral karyotyping (SKY): a visual comparison. Cytogenet Cell Genet 82:83-87 (1998).

Betts DR, Cohen N, Leibundgut KE, Kuhne T, Caflisch U, Greiner J, Traktenbrot L, Niggli FK: Characterization of karyotypic events and evolution in neuroblastoma. Pediatr Blood Cancer 44:147-157 (2005).

Bible KC, Boerner SA, Kirkland K, Anderl KL, Bartelt D Jr, Svingen PA, Kottke TJ, Lee YK, Eckdahl S, Stalboerger PG, Jenkins RB, Kaufmann $\mathrm{SH}$ : Characterization of an ovarian carcinoma cell line resistant to cisplatin and flavopiridol. Clin Cancer Res 6:661-670 (2000).

Borg I, Squire M, Menzel C, Stout K, Morgan D, Willatt L, O’Brien PC, Ferguson-Smith MA, Ropers HH, Tommerup N, Kalscheuer VM, Sargan DR: A cryptic deletion of 2 q 35 including part of the PAX3 gene detected by breakpoint mapping in a child with autism and a de novo 2;8 translocation. J Med Genet 39:391-399 (2002).

Buwe A, Steinlein C, Koehler MR, Bar-Am I, Katzin N, Schmid M: Multicolor spectral karyotyping of rat chromosomes. Cytogenet Genome Res 103:163-168 (2003)

Calabrese G, Fantasia D, Franch PG, Morizio E, Stuppia L, Gatta V, Olioso P, Mingarelli R, Spadano A, Palka G: Spectral karyotyping (SKY) refinement of a complex karyotype with $t(20 ; 21)$ in a Ph-positive CML patient submitted to peripheral blood stem cell transplantation. Bone Marrow Transplant 26:1125-1127 (2000a).

Calabrese G, Fantasia D, Spadano A, Morizio E, Di Bartolomeo P, Palka G: Karyotype refinement in five patients with acute myeloid leukemia using spectral karyotyping. Haematologica 85: 1219-1221 (2000b)

Calabrese G, Taraborelli T, Fantasia D, Guanciali Franchi P, Spadano A, Palka G: Karyotype refinement by multicolor fluorescence in situ hybridization analysis in 18 patients with acute lymphoblastic leukemia. Haematologica 87: 888-889 (2002)

Calabrese G, Fantasia D, Morizio E, Toro PM, Franchi PG, Fornaro A, Spadano A, Stuppia L, Palka G: Chromosome 11 rearrangements and specific MLL amplification revealed by spectral karyotyping in a patient with refractory anaemia with excess of blasts (RAEB). Br J Haematol 122:760-763 (2003).

Carlotti CG Jr, Drake JM, Hladky JP, Teshima I, Becker LE, Rutka JT: Primary Ewing's sarcoma of the skull in children. Utility of molecular diagnostics, surgery and adjuvant therapies. Pediatr Neurosurg 31:307-315 (1999).
Chan KY, Wong N, Lai PB, Squire JA, Macgregor PF, Beheshti B, Albert M, To KF, Johnson PJ: Transcriptional profiling on chromosome 19p indicated frequent downregulation of ACP5 expression in hepatocellular carcinoma. Int Cancer 114:902-908 (2005)

Chen CP, Lin SP, Lin CC, Li YC, Hsieh LJ, Lee CC, Chen YJ, Wang W: Spectral karyotyping and fluorescence in situ hybridization analysis of de novo partial duplication of $\mathrm{Yq}(\mathrm{Yq} 11.2 \rightarrow$ qter $)$ and partial monosomy $5 \mathrm{p}$ ( 5 p15.3 $\rightarrow$ pter $)$. Prenat Diagn 25:723-725 (2005)

Chen Z, Coffin CM, Scott S, Meloni-Ehrig A Shepard R, Issa B, Forsyth DR, Sandberg AA, et al: Evidence by spectral karyotyping that $8 \mathrm{q} 11.2$ is nonrandomly involved in lipoblastoma. J Mol Diagn 2:73-77 (2000).

Cigudosa JC, Odero MD, Calasanz MJ, Sole F, Salido M, Arranz E, Martinez-Ramirez A, Urioste M, Alvarez S, Cervera JV, MacGrogan D, Sanz MA, Nimer SD, Benitez J: De novo erythroleukemia chromosome features include multiple rearrangements, with special involvement of chromosomes 11 and 19. Genes Chromosomes Cancer 36:406-412 (2003).

Clarkson B, Pavenski K, Dupuis L, Kennedy S, Meyn S, Nezarati MM, Nie G, Weksberg R, Withers S, Quercia N, Teebi AS, Teshima I: Detecting rearrangements in children using subtelomeric FISH and SKY. Am J Med Genet 107: 267-274 (2002)

Coleman AE, Ried T, Janz S: Chromosomes 1 and 5 harbor plasmacytoma progressor genes in mice. Genes Chromosomes Cancer 29:70-74 (2000).

Cottage A, Dowen S, Roberts I, Pett M, Coleman N, Stanley M: Early genetic events in HPV immortalised keratinocytes. Genes Chromosomes Cancer 30:72-79 (2001).

Deans B, Griffin CS, O'Regan P, Jasin M, Thacker $\mathrm{J}$ : Homologous recombination deficiency leads to profound genetic instability in cells derived from Xrcc2-knockout mice. Cancer Res 63: 8181-8187 (2003).

Deng W, Tsao SW, Guan XY, Lucas JN, Si HX, Leung CS, Mak P, Wang LD, Cheung AL: Distinct profiles of critically short telomeres are a key determinant of different chromosome aberrations in immortalized human cells: wholegenome evidence from multiple cell lines. Oncogene 23:9090-9101 (2004)

Elghezal H, Le Guyader G, Radford-Weiss I, Perot C, Van Den Akker J, Eydoux P, Vekemans M, Romana SP: Reassessment of childhood B-lineage lymphoblastic leukemia karyotypes using spectral analysis. Genes Chromosomes Cancer 30:383-392 (2001)

Fadl-Elmula I, Kytola S, Pan Y, Lui WO, Derienzo G, Forsberg L, Mandahl N, Gorunova L, Bergerheim US, Heim S, Larsson C: Characterization of chromosomal abnormalities in uroepithelial carcinomas by G-banding, spectral karyotyping and FISH analysis. Int J Cancer 92:824-831 (2001).

Fan YS, Zhang Y, Speevak M, Farrell S, Jung JH, Siu VM: Detection of submicroscopic aberrations in patients with unexplained mental retardation by fluorescence in situ hybridization using multiple subtelomeric probes. Genet Med 3: 416-421 (2001)

Ferguson DO, Sekiguchi JM, Chang S, Frank KM, Gao Y, DePinho RA, Alt FW: The nonhomologous end-joining pathway of DNA repair is required for genomic stability and the suppression of translocations. Proc Natl Acad Sci USA 97:6630-6633 (2000). 
Frank O, Rudolph C, Heberlein C, von Neuhoff N, Schrock E, Schambach A, Schlegelberger B, Fehse B, Ostertag W, Stocking C, Baum C: Tumor cells escape suicide gene therapy by genetic and epigenetic instability. Blood 104:35433549 (2004).

Garini Y, Gil A, Bar-Am I, Cabib D, Katzir N: Signal to noise analysis of multiple color fluorescence imaging microscopy. Cytometry 35:214-226 (1999).

Ghadimi BM, Schrock E, Walker RL, Wangsa D, Jauho A, Meltzer PS, Ried T: Specific chromosomal aberrations and amplification of the AIB1 nuclear receptor coactivator gene in pancreatic carcinomas. Am J Pathol 154:525-536 (1999)

Ghadimi BM, Sackett DL, Difilippantonio MJ Schrock E, Neumann T, Jauho A, Auer G, Ried $\mathrm{T}$ : Centrosome amplification and instability occurs exclusively in aneuploid, but not in diploid colorectal cancer cell lines, and correlates with numerical chromosomal aberrations. Genes Chromosomes Cancer 27:183-190 (2000).

Guanciali-Franchi P, Calabrese G, Morizio E, Fantasia D, Colosimo A, Rinaldi MM, Cristini L, Simonelli A, Lonardo F, Turci A, Zatterale A, Lagana C, Stuppia L, Sabatino G, Palka G: Identification of 14 rare marker chromosomes and derivatives by spectral karyotyping in prenatal and postnatal diagnosis. Am J Med Genet A 127:144-148 (2004)

Guda K, Upender MB, Belinsky G, Flynn C, Nakanishi M, Marino JN, Ried T, Rosenberg DW: Carcinogen-induced colon tumors in mice are chromosomally stable and are characterized by low-level microsatellite instability. Oncogene 23:3813-3821 (2004)

Guttenbach M, Steinlein C, Engel W, Schmid M: Cytogenetic characterization of the TM4 mouse Sertoli cell line. I. Conventional banding techniques, FISH and SKY. Cytogenet Cell Genet 94:71-78 (2001)

Haddad BR, Schrock E, Meck J, Cowan J, Young H, Ferguson-Smith MA, du Manoir S, Ried T: Identification of de novo chromosomal markers and derivatives by spectral karyotyping. Hum Genet 103:619-625 (1998).

Hao LY, Greider CW: Genomic instability in both wild-type and telomerase null MEFs. Chromosoma 113:62-68 (2004)

Harding MA, Arden KC, Gildea JW, Gildea JJ, Perlman EJ, Viars C, Theodorescu D: Functional genomic comparison of lineage-related human bladder cancer cell lines with differing tumorigenic and metastatic potentials by spectral karyotyping, comparative genomic hybridization, and a novel method of positional expression profiling. Cancer Res 62:6981-6989 (2002).

Hardt T, Himmelbauer H, Mann W, Ropers H, Haaf T: Towards identification of individual homologous chromosomes: comparative genomic hybridization and spectral karyotyping discriminate between paternal and maternal euchromatin in Mus musculus $\times$ M. spretus interspecific hybrids. Cytogenet Cell Genet 86: 187-193 (1999).

Harris CP, Lu XY, Narayan G, Singh B, Murty VV, Rao PH: Comprehensive molecular cytogenetic characterization of cervical cancer cell lines. Genes Chromosomes Cancer 36:233-241 (2003).

Harris DL, Siu BL, Hummel M, Harbert K, Senft J, Sargent L, Wenger SL: Mosaic ring 12p and total anomalous pulmonary venous return. Am Med Genet A 131:91-93 (2004).
Helmrich A, Lee S, O'Brien P, Dorken B, Lowe SW, Schrock E, Schmitt CA: Recurrent chromosomal aberrations in INK4a/ARF defective primary lymphomas predict drug responses in vivo. Oncogene 24:4174-4182 (2005).

Heng HH, Ye CJ, Yang F, Ebrahim S, Liu G, Bremer SW, Thomas CM, Ye J, Chen TJ, Tuck-Muller C Yu JW, Krawetz SA, Johnson A: Analysis of marker or complex chromosomal rearrangements present in pre- and post-natal karyotypes utilizing a combination of G-banding, spectral karyotyping and fluorescence in situ hybridization. Clin Genet 63:358-367 (2003).

Hermsen M, Snijders A, Guervos MA, Taenzer S, Koerner U, Baak J, Pinkel D, Albertson D, van Diest P, Meijer G, Schrock E: Centromeric chromosomal translocations show tissue-specific differences between squamous cell carcinomas and adenocarcinomas. Oncogene 24: 1571-1579 (2005)

Hida K, Hida Y, Amin DN, Flint AF, Panigrahy D, Morton CC, Klagsbrun M: Tumor-associated endothelial cells with cytogenetic abnormalities. Cancer Res 64:8249-8255 (2004).

Hilgenfeld E, Padilla-Nash H, McNeil N, Knutsen T, Montagna C, Tchinda J, Horst J, Ludwig WD Serve H, Buchner T, Berdel WE, Schrock E, Ried T: Spectral karyotyping and fluorescence in situ hybridization detect novel chromosomal aberrations, a recurring involvement of chromosome 21 and amplification of the MYC oncogene in acute myeloid leukaemia M2. Br J Haematol 113:305-317 (2001)

Hodges CA, Ilagan A, Jennings D, Keri R, Nilson J, Hunt PA: Experimental evidence that changes in oocyte growth influence meiotic chromosome segregation. Hum Reprod 17:1171-1180 (2002).

Houge G, Liehr T, Schoumans J, Ness GO, Solland $\mathrm{K}$, Starke H, Claussen U, Stromme P, Akre B, Vermeulen S: Ten years follow up of a boy with a complex chromosomal rearrangement: going from a $>5$ to 15 -breakpoint CCR. Am J Med Genet A 118:235-240 (2003)

Hsieh LJ, Hsieh TC, Yeh GP, Lin MI, Chen M, Wang BB: Prenatal diagnosis of a fetus affected with Down syndrome and deletion 1p36 syndrome by fluorescence in situ hybridization and spectral karyotyping. Fetal Diagn Ther 19:356-360 (2004).

Hu Y, Pang E, Lai PB, Squire JA, MacGregor PF Beheshti B, Albert M, Leung TW, Wong N: Genetic alterations in doxorubicin-resistant hepatocellular carcinoma cells: a combined study of spectral karyotyping, positional expression profiling and candidate genes. Int J Oncol 25: 1357-1364 (2004)

Huang B, Ning Y, Lamb AN, Sandlin CJ, Jamehdor M, Ried T, Bartley J: Identification of an un usual marker chromosome by spectral karyotyping. Am J Med Genet 80:368-372 (1998).

Imamura T, Kakazu N, Hibi S, Morimoto A, Fukushima Y, Ijuin I, Hada S, Kitabayashi I, Abe T, Imashuku S: Rearrangement of the $M O Z$ gene in pediatric therapy-related myelodysplastic syndrome with a novel chromosomal translocation $\mathrm{t}(2 ; 8)(\mathrm{p} 23 ; \mathrm{p} 11)$. Genes Chromosomes Cancer 36:413-419 (2003).

Joyama S, Ueda T, Shimizu K, Kudawara I, Mano M, Funai H, Takemura K, Yoshikawa H: Chromosome rearrangement at $17 \mathrm{q} 25$ and Xp11.2 in alveolar soft-part sarcoma: A case report and review of the literature. Cancer 86:1246-1250 (1999).

Jyoko N, Kuroda J, Kimura S, Kobayashi Y, Yoshikawa $\mathrm{T}$ : Comprehensive cytogenetic study by spectral karyotyping on blastic natural killer cell leukemia/lymphoma. Am J Hematol 69: 234-235 (2002).
Kakazu N, Taniwaki M, Horiike S, Nishida K, Tatekawa T, Nagai M, Takahashi T, Akaogi T, et al: Combined spectral karyotyping and DAPI banding analysis of chromosome abnormalities in myelodysplastic syndrome. Genes Chromosomes Cancer 26:336-345 (1999).

Kakazu N, Kito K, Hitomi T, Oita J, Nishida K, Masuda $\mathrm{K}$, Miki T, Abe T: Characterization of complex chromosomal abnormalities in B-cell lymphoma by a combined spectral karyotyping (SKY) analysis and fluorescence in situ hybridization (FISH) using a 14q telomere probe. Am J Hematol 65:291-297 (2000).

Kanayama H, Lui WO, Takahashi M, Naroda T, Kedra D, Wong FK, Kuroki Y, Nakahori Y, Larsson C, Kagawa S, Teh BT: Association of a novel constitutional translocation $\mathrm{t}(\mathrm{lq} ; 3 \mathrm{q})$ with familial renal cell carcinoma. J Med Genet 38 165-170 (2001).

Karlsson A, Deb-Basu D, Cherry A, Turner S, Ford J, Felsher DW: Defective double-strand DNA break repair and chromosomal translocations by MYC overexpression. Proc Natl Acad Sci USA 100:9974-9979 (2003).

Kelly L, Clark J, Gilliland DG: Comprehensive genotypic analysis of leukemia: clinical and therapeutic implications. Curr Opin Oncol 14:1018 (2002).

Knutsen T, Pack S, Petropavlovskaja M, PadillaNash H, Knight C, Mickley LA, Ried T, Elwood PC, Roberts SJ: Cytogenetic, spectral karyotyping, fluorescence in situ hybridization, and comparative genomic hybridization characterization of two new secondary leukemia cell lines with $5 \mathrm{q}$ deletions, and $M Y C$ and $M L L$ amplification. Genes Chromosomes Cancer 37 270-281 (2003)

Knutsen T, Gobu V, Knaus R, Padilla-Nash H, Augustus M, Strausberg RL, Kirsch IR, Sirotkin K, Ried T: The interactive online SKY/M-FISH and CGH database and the Entrez cancer chromosomes search database: linkage of chromosomal aberrations with the genome sequence. Genes Chromosomes Cancer 44:52-64 (2005).

Kotchetkov R, Cinatl J, Blaheta R, Vogel JU, Karaskova J, Squire J, Hernaiz Driever P, Klingebiel T, Cinatl J Jr: Development of resistance to vin cristine and doxorubicin in neuroblastoma alters malignant properties and induces additional karyotype changes: a preclinical model. Int J Cancer 104:36-43 (2003).

Kotzot D, Holland H, Kohler M, Froster UG: A complex chromosome rearrangement involving chromosome 8,11 , and 12 analyzed by conventional cytogenetic investigations, fluorescence in situ hybridisation, and spectral karyotyping. Ann Genet 44:135-138 (2001).

Krex D, Mohr B, Hauses M, Ehninger G, Schackert HK, Schackert G: Identification of uncommon chromosomal aberrations in the neuroglioma cell line $\mathrm{H} 4$ by spectral karyotyping. J Neurooncol 52:119-128 (2001)

Kubota H, Nishizaki T, Harada K, Harada K, Oga A, Ito $\mathrm{H}$, Suzuki M, Sasaki K: Identification of recurrent chromosomal rearrangements and the unique relationship between low-level amplification and translocation in glioblastoma. Genes Chromosomes Cancer 31:125-133 (2001).

Kullendorff CM, Mertens F, Donner M, Wiebe T, Akerman M, Mandahl N: Cytogenetic aberrations in Ewing sarcoma: are secondary changes associated with clinical outcome? Med Pediat Oncol 32:79-83 (1999).

Kuroda J, Kimura S, Akaogi T, Hayashi H, Nishida K, Kakazu N, Abe T: Aggressive natural killer cell leukemia/lymphoma: a comprehensive cytogenetic study by spectral karyotyping. Ann Hematol 79:519-522 (2000). 
Kytola S, Rummukainen J, Nordgren A, Karhu R, Farnebo F, Isola J, Larsson C: Chromosomal alterations in 15 breast cancer cell lines by comparative genomic hybridization and spectral karyotyping. Genes Chromosomes Cancer 28: 308-317 (2000).

Lau CC, Harris CP, Lu XY, Perlaky L, Gogineni S, Chintagumpala M, Hicks J, Johnson ME, et al: Frequent amplification and rearrangement of chromosomal bands $6 \mathrm{p} 12 \rightarrow \mathrm{p} 21$ and $17 \mathrm{p} 11.2$ in osteosarcoma. Genes Chromosomes Cancer 39:11-21 (2004)

Le Beau MM, Bitts S, Davis EM, Kogan SC: Recurring chromosomal abnormalities in leukemia in PML-RARA transgenic mice parallel human acute promyelocytic leukemia. Blood 99:29852991 (2002).

Le Beau MM, Davis EM, Patel B, Phan VT, Sohal J, Kogan SC: Recurring chromosomal abnormalities in leukemia in PML-RARA transgenic mice identify cooperating events and genetic pathways to acute promyelocytic leukemia. Blood 102:1072-1074 (2003).

Lee C, Gisselsson D, Jin C, Nordgren A, Ferguson DO, Blennow E, Fletcher JA, Morton CC: Limitations of chromosome classification by multicolor karyotyping. Am J Hum Genet 68:10431047 (2001)

Leppig KA, Ball S, Au K, Opheim KE, Norwood T: Familial cryptic $(20 ; 21)$ translocation identified by in situ hybridization technologies. Am J Med Genet 93:273-277 (2000).

Lindvall C, Nordenskjold M, Porwit A, Bjorkholm $\mathrm{M}$, Blennow E: Molecular cytogenetic characterization of acute myeloid leukemia and myelodysplastic syndromes with multiple chromosome rearrangements. Haematologica 86 1158-1164 (2001).

Lindvall C, Furge K, Bjorkholm M, Guo X, Haab B, Blennow E, Nordenskjold M, Teh BT: Combined genetic and transcriptional profiling of acute myeloid leukemia with normal and complex karyotypes. Haematologica 89:1072-1081 (2004).

Liu J, Blackhall F, Seiden-Long I, Jurisica I, Navab R, Liu N, Radulovich N, Wigle D, et al: Modeling of lung cancer by an orthotopically growing H460SM variant cell line reveals novel candidate genes for systemic metastasis. Oncogene 23:6316-6324 (2004)

Liyanage M, Coleman A, du Manoir S, Veldman T, McCormack S, Dickson RB, Barlow C, Wynshaw-Boris A, Janz S, Wienberg J, FergusonSmith MA, Schrock E, Ried T: Multicolour spectral karyotyping of mouse chromosomes. Nat Genet 14:312-315 (1996).

Lu XY, Harris CP, Cooley L, Margolin J, Steuber PC, Sheldon M, Rao PH, Lau CC: The utility of spectral karyotyping in the cytogenetic analysis of newly diagnosed pediatric acute lymphoblastic leukemia. Leukemia 16:2222-2227 (2002).

Lualdi E, Modena P, Debiec-Rychter M, Pedeutour F, Teixeira MR, Facchinetti F, Dagrada GP, Pilotti S, Sozzi G: Molecular cytogenetic characterization of proximal-type epithelioid sarcoma. Genes Chromosomes Cancer 41:283-290 (2004).

Lui WO, Kytola S, Anfalk L, Larsson C, Farnebo LO: Balanced translocation $(3 ; 7)(\mathrm{p} 25 ; \mathrm{q} 34)$ : another mechanism of tumorigenesis in follicular thyroid carcinoma? Cancer Genet Cytogenet 119:109-112 (2000).

MacLeod RA, Spitzer D, Bar-Am I, Sylvester JE, Kaufmann M, Wernich A, Drexler HG: Karyotypic dissection of Hodgkin's disease cell lines reveals ectopic subtelomeres and ribosomal DNA at sites of multiple jumping translocations and genomic amplification. Leukemia 14:18031814 (2000).
Marquez C, Cohen J, Munne S: Chromosome identification in human oocytes and polar bodies by spectral karyotyping. Cytogenet Cell Genet 81 : 254-258 (1998).

Mathew S, Rao PH, Dalton J, Downing JR, Raimondi SC: Multicolor spectral karyotyping identifies novel translocations in childhood acute lymphoblastic leukemia. Leukemia 15:468-472 (2001).

Matsui S, Sait S, Jones CA, Nowak N, Gross KW: Rapid localization of transgenes in mouse chromosomes with a combined Spectral Karyotyping/FISH technique. Mamm Genome 13:680685 (2002).

Matthaei A, Werner W, Gerlach EM, Koerner U, Tinschert S, Nitz I, Herr A, Rump A, Bartsch O, Hinkel KG, Schrock E, Oexle K: Small reciprocal insertion detected by spectral karyotyping (SKY) and delimited by array-CGH analysis. Eur J Med Genet 48:328-338 (2005).

McCormack SJ, Weaver Z, Deming S, Natarajan G, Torri J, Johnson MD, Liyanage M, Ried T, Dickson RB: Myc/p53 interactions in transgenic mouse mammary development, tumorigenesis and chromosomal instability. Oncogene 16: 2755-2766 (1998)

McHugh MM, Gawron LS, Matsui S, Beerman TA The antitumor enediyne C-1027 alters cell cycle progression and induces chromosomal aberrations and telomere dysfunction. Cancer Res 65: 5344-5351 (2005)

Mehra S, Messner H, Minden M, Chaganti RS: Molecular cytogenetic characterization of nonHodgkin lymphoma cell lines. Genes Chromosomes Cancer 33:225-234 (2002).

Melcher R, von Golitschek R, Steinlein C, Schindler D, Neitzel H, Kainer K, Schmid M, Hoehn H: Spectral karyotyping of Werner syndrome fibroblast cultures. Cytogenet Cell Genet 91: 180-185 (2000).

Melcher R, Koehler S, Steinlein C, Schmid M, Mueller CR, Luehrs H, Menzel T, Scheppach W, Moerk H, Scheurlen M, Koehrle J, Al-Taie O: Spectral karyotype analysis of colon cancer cell lines of the tumor suppressor and mutator pathway. Cytogenet Genome Res 98:22-28 (2002).

Menzel T, Melcher R, Koehler S, Dusel G, Backhaus K, Ott G, Breithaupt W, Al-Taie O, Schauber J, Gostner A, Scheppach W, Luhrs H: Establishment of a colonic adenoma cell line (GEKI-2): spectral karyotype analysis and functional characterization. Int J Colorectal Dis 19:12-17 (2004).

Modlich U, Kustikova OS, Schmidt M, Rudolph C, Meyer J, Li Z, Kamino K, von Neuhoff N, et al: Leukemias following retroviral transfer of multidrug resistance 1 (MDR1) are driven by combinatorial insertional mutagenesis. Blood 105: 4235-4246 (2005).

Mohr B, Illmer T: Structural chromosomal aberrations in the colon cancer cell line HCT 116 - results of investigations based on spectral karyotyping. Cytogenet Genome Res 108:359-361 (2005).

Mohr B, Bornhauser M, Thiede C, Schakel U, Schaich M, Illmer T, Pascheberg U, Ehninger G: Comparison of spectral karyotyping and conventional cytogenetics in 39 patients with acute myeloid leukemia and myelodysplastic syndrome. Leukemia 14:1031-1038 (2000).

Montagna C, Andrechek ER, Padilla-Nash H, Muller WJ, Ried T: Centrosome abnormalities, recurring deletions of chromosome 4 , and genomic amplification of $H E R 2 / n e u$ define mouse mammary gland adenocarcinomas induced by mutant HER2/neu. Oncogene 21:890-898 (2002).
Montagna C, Lyu MS, Hunter K, Lukes L, Lowther W, Reppert T, Hissong B, Weaver Z, Ried T: The Septin $9(M S F)$ gene is amplified and overexpressed in mouse mammary gland adenocarcinomas and human breast cancer cell lines. Cancer Res 63:2179-2187 (2003).

Moore CM, Janish C, Eddy CA, Hubbard GB, Leland MM, Rogers J: Cytogenetic and fertility studies of a rheboon, rhesus macaque (Macaca mulatta) $\times$ baboon (apio hamadryas) cross: further support for a single karyotype nomenclature. Am J Phys Anthropol 110:119-127 (1999).

Mrozek K, Heinonen K, Theil KS, Bloomfield CD Spectral karyotyping in patients with acute myeloid leukemia and a complex karyotype shows hidden aberrations, including recurrent overrepresentation of $21 \mathrm{q}, 11 \mathrm{q}$, and $22 \mathrm{q}$. Genes Chromosomes Cancer 34:137-153 (2002).

Musio A, Montagna C, Zambroni D, Indino E, Barbieri O, Citti L, Villa A, Ried T, Vezzoni P: Inhibition of BUB1 results in genomic instability and anchorage-independent growth of normal human fibroblasts. Cancer Res 63:2855-2863 (2003).

Nanjangud G, Rao PH, Hegde A, Teruya-Feldstein J, Donnelly G, Qin J, Jhanwar SC, Zelenetz AD, Chaganti RS: Spectral karyotyping identifies new rearrangements, translocations, and clinical associations in diffuse large B-cell lymphoma. Blood 99:2554-2561 (2002).

Naus NC, van Drunen E, de Klein A, Luyten GP, Paridaens DA, Alers JC, Ksander BR, Beverloo $\mathrm{HB}$, Slater RM: Characterization of complex chromosomal abnormalities in uveal melanoma by fluorescence in situ hybridization, spectral karyotyping, and comparative genomic hybridization. Genes Chromosomes Cancer 30: 267-273 (2001).

Ning Y, Laundon CH, Schrock E, Buchanan P, Ried T: Prenatal diagnosis of a mosaic extra structurally abnormal chromosome by spectral karyotyping. Prenat Diagn 19:480-482 (1999).

Nomura K, Kanda-Akano Y, Shimizu D, Okuda T, Yoshida N, Matsumoto Y, Nishida K, Taki T, Yokota S, Horiike S, Taniwaki M: An additional segment at $1 p 36$ derived from $\operatorname{der}(18) t(14 ; 18)$ in patients with diffuse large $\mathrm{B}$-cell lymphomas transformed from follicular lymphoma. Ann Hematol 84:474-476 (2005).

Nordgren A, Farnebo F, Johansson B, Holmgren G, Forestier E, Larsson C, Soderhall S, Nordenskjold M, Blennow E: Identification of numerical and structural chromosome aberrations in 15 high hyperdiploid childhood acute lymphoblastic leukemias using spectral karyotyping. Eur J Haematol 66:297-304 (2001a).

Nordgren A, Schoumans J, Soderhall S, Nordenskjold $\mathrm{M}$, Blennow E: Interphase fluorescence in situ hybridization and spectral karyotyping reveals hidden genetic aberrations in children with acute lymphoblastic leukaemia and a normal banded karyotype. Br J Haematol 114:786793 (2001b)

Nordgren A, Heyman M, Sahlen S, Schoumans J, Soderhall S, Nordenskjold M, Blennow E: Spectral karyotyping and interphase FISH reveal abnormalities not detected by conventional Gbanding. Implications for treatment stratification of childhood acute lymphoblastic leukaemia: detailed analysis of 70 cases. Eur J Haematol 68:31-41 (2002).

Odero MD, Carlson K, Calasanz MJ, Lahortiga I, Chinwalla V, Rowley JD: Identification of new translocations involving ETV6 in hematologic malignancies by fluorescence in situ hybridization and spectral karyotyping. Genes Chromosomes Cancer 31:134-142 (2001). 
Pan Y, Kytola S, Farnebo F, Wang N, Lui WO, Nupponen N, Isola J, Visakorpi T, Bergerheim US, Larsson C: Characterization of chromosomal abnormalities in prostate cancer cell lines by spectral karyotyping. Cytogenet Cell Genet 87: 225-232 (1999).

Pandita A, Zielenska M, Thorner P, Bayani J, Godbout R, Greenberg M, Squire JA: Application of comparative genomic hybridization, spectral karyotyping, and microarray analysis in the identification of subtype-specific patterns of genomic changes in rhabdomyosarcoma. Neoplasia 1:262-275 (1999).

Pang E, Wong N, Lai PB, To KF, Lau JW, Johnson PJ: A comprehensive karyotypic analysis on a newly developed hepatocellular carcinoma cell line, HKCI-1, by spectral karyotyping and comparative genomic hybridization. Cancer Genet Cytogenet 121:9-16 (2000).

Pang E, Wong N, Lai PB, To KF, Lau WY, Johnson PJ: Consistent chromosome 10 rearrangements in four newly established human hepatocellular carcinoma cell lines. Genes Chromosomes Cancer 33:150-159 (2002).

Parham DM, Bridge JA, Lukacs JL, Ding Y, Tryka AF, Sawyer JR: Cytogenetic distinction among benign fibro-osseous lesions of bone in children and adolescents: value of karyotypic findings in differential diagnosis. Pediatr Dev Pathol 7:148-158 (2004).

Pavlovich CP, Padilla-Nash H, Wangsa D, Nickerson ML, Matrosova V, Linehan WM, Ried T, Phillips JL: Patterns of aneuploidy in stage IV clear cell renal cell carcinoma revealed by comparative genomic hybridization and spectral karyotyping. Genes Chromosomes Cancer 37: 252-260 (2003).

Pellestor F, Anahory T, Hamamah S: The chromosomal analysis of human oocytes. An overview of established procedures. Hum Reprod Update 11:15-32 (2005).

Peschka B, Leygraaf J, Hansmann D, Hansmann M, Schrock E, Ried T, Engels H, Schwanitz G, Schubert R: Analysis of a de novo complex chromosome rearrangement involving chromosomes 4, 11, 12 and 13 and eight breakpoints by conventional cytogenetic, fluorescence in situ hybridization and spectral karyotyping. Prenat Diagn 19:1143-1149 (1999).

Phelan MC, Blackburn W, Rogers RC, Crawford EC, Cooley NR Jr, Schrock E, Ning Y, Ried T: FISH analysis of a complex chromosome rearrangement involving nine breakpoints on chromosomes 6, 12, 14 and 16. Prenat Diagn 18: $1174-1180$ (1998).

Phillips JL, Ghadimi BM, Wangsa D, Padilla-Nash $\mathrm{H}$, Worrell R, Hewitt S, Walther M, Linehan WM, et al: Molecular cytogenetic characterization of early and late renal cell carcinomas in von Hippel-Lindau disease. Genes Chromosomes Cancer 31:1-9 (2001).

Pons M, Cigudosa JC, Rodriguez-Perales S, Bella JL, Gonzalez C, Gamallo C, Quintanilla M: Chromosomal instability and phenotypic plasticity during the squamous-spindle carcinoma transition: association of a specific $\mathrm{T}(14 ; 15)$ with malignant progression. Oncogene 24:76087618 (2005).

Popescu NC: Comprehensive genetic analysis of cancer cells. J Cell Mol Med 4:151-163 (2000).

Qi L, Strong MA, Karim BO, Huso DL, Greider CW: Telomere fusion to chromosome breaks reduces oncogenic translocations and tumor formation. Nat Cell Biol 7:706-711 (2005).

Ragin CC, Reshmi SC, Gollin SM: Mapping and analysis of HPV16 integration sites in a head and neck cancer cell line. Int J Cancer 110:701709 (2004).
Rao PH, Cigudosa JC, Ning Y, Calasanz MJ, Iida S, Tagawa S, Michaeli J, Klein B, Dalla-Favera R, Jhanwar SC, Ried T, Chaganti RS: Multicolor spectral karyotyping identifies new recurring breakpoints and translocations in multiple myeloma. Blood 92:1743-1748 (1998).

Rao PH, Harris CP, Yan Lu X, Li XN, Mok SC, Lau CC: Multicolor spectral karyotyping of serous ovarian adenocarcinoma. Genes Chromosomes Cancer 33:123-132 (2002).

Reddy KS, Wang S, Groh S, Gonatos J: SKY assessment of two karyotypes with 0-6 supernumerary marker/ring chromosomes and review of previously reported cases with two or more markers. Am J Med Genet A 118:156-171 (2003).

Rehen SK, McConnell MJ, Kaushal D, Kingsbury MA, Yang AH, Chun J: Chromosomal variation in neurons of the developing and adult mammalian nervous system. Proc Natl Acad Sci USA 98:13361-13366 (2001).

Rennstam K, Baldetorp B, Kytola S, Tanner M, Isola J: Chromosomal rearrangements and oncogene amplification precede aneuploidization in the genetic evolution of breast cancer. Cancer Res 61:1214-1219 (2001).

Reshmi SC, Saunders WS, Kudla DM, Ragin CR, Gollin SM: Chromosomal instability and marker chromosome evolution in oral squamous cell carcinoma. Genes Chromosomes Cancer 41:38-46 (2004).

Roberts I, Gordon A, Wang R, Pritchard-Jones K, Shipley J, Coleman N: Molecular cytogenetic analysis consistently identifies translocations involving chromosomes 1, 2 and 15 in five embryonal rhabdomyosarcoma cell lines and a PAX-FOXO1A fusion gene negative alveolar rhabdomyosarcoma cell line. Cytogenet Cell Genet 95:134-142 (2001).

Rodriguez-Perales S, Martinez-Ramirez A, de Andres SA, Valle L, Urioste M, Benitez J, Cigudosa JC: Molecular cytogenetic characterization of rhabdomyosarcoma cell lines. Cancer Genet Cytogenet 148:35-43 (2004).

Roschke AV, Tonon G, Gehlhaus KS, McTyre N, Bussey KJ, Lababidi S, Scudiero DA, Weinstein JN, Kirsch IR: Karyotypic complexity of the NCI-60 drug-screening panel. Cancer Res 63: 8634-8647 (2003).

Rowley JD, Reshmi S, Carlson K, Roulston D: Spectral karyotype analysis of T-cell acute leukemia. Blood 93:2038-2042 (1999).

Sait SN, Qadir MU, Conroy JM, Matsui S, Nowak NJ, Baer MR: Double minute chromosomes in acute myeloid leukemia and myelodysplastic syndrome: identification of new amplification regions by fluorescence in situ hybridization and spectral karyotyping. Genes Chromosomes Cancer 34:42-47 (2002).

Samper E, Goytisolo FA, Menissier-de Murcia J, Gonzalez-Suarez E, Cigudosa JC, de Murcia G, Blasco MA: Normal telomere length and chromosomal end capping in poly(ADP-ribose) polymerase-deficient mice and primary cells despite increased chromosomal instability. J Cell Biol 154:49-60 (2001)

Sandalinas M, Marquez C, Munne S: Spectral karyotyping of fresh, non-inseminated oocytes. Mol Hum Reprod 8:580-585 (2002).

Sargent LM, Senft JR, Lowry DT, Jefferson AM, Tyson FL, Malkinson AM, Coleman AE, Reynolds SH: Specific chromosomal aberrations in mouse lung adenocarcinoma cell lines detected by spectral karyotyping: a comparison with human lung adenocarcinoma. Cancer Res 62: 1152-1157 (2002)
Sawyer JR, Lukacs JL, Munshi N, Desikan KR, Singhal S, Mehta J, Siegel D, Shaughnessy J, Barlogie $B$ : Identification of new nonrandom translocations in multiple myeloma with multicolor spectral karyotyping. Blood 92:4269-4278 (1998).

Sawyer JR, Lukacs JL, Thomas EL, Swanson CM, Goosen LS, Sammartino G, Gilliland JC, Munshi NC, et al: Multicolour spectral karyotyping identifies new translocations and a recurring pathway for chromosome loss in multiple myeloma. Br J Haematol 112:167-174 (2001).

Sawyer JR, Tricot G, Lukacs JL, Binz RL, Tian E, Barlogie B, Shaughnessy J Jr: Genomic instability in multiple myeloma: evidence for jumping segmental duplications of chromosome arm 1q. Genes Chromosomes Cancer 42:95-106 (2005).

Schaeffer AJ, Nguyen M, Liem A, Lee D, Montagna C, Lambert PF, Ried T, Difilippantonio MJ: E6 and E7 oncoproteins induce distinct patterns of chromosomal aneuploidy in skin tumors from transgenic mice. Cancer Res 64:538-546 (2004).

Schreurs MW, Hermsen MA, Klein Geltink RI Scholten KB, Brink AA, Kueter EW, Tijssen M, Meijer CJ, et al: Genomic stability and functional activity may be lost in telomerase transduced human CD8+ T lymphocytes. Blood 106 : 2663-2670 (2005).

Schrock E, Padilla-Nash H: Spectral karyotyping and multicolor fluorescence in situ hybridization reveal new tumor-specific chromosomal aberrations. Semin Hematol 37:334-347 (2000).

Schrock E, du Manoir S, Veldman T, Schoell B, Wienberg J, Ferguson-Smith MA, Ning Y, Ledbetter DH, et al: Multicolor spectral karyotyping of human chromosomes. Science 273:494497 (1996).

Schrock E, Veldman T, Padilla-Nash H, Ning Y, Spurbeck J, Jalal S, Shaffer LG, Papenhausen P, et al: Spectral karyotyping refines cytogenetic diagnostics of constitutional chromosomal abnormalities. Hum Genet 101:255-262 (1997).

Shen SX, Weaver Z, Xu X, Li C, Weinstein M, Chen L, Guan XY, Ried T, Deng CX: A targeted disruption of the murine Brcal gene causes gamma-irradiation hypersensitivity and genetic instability. Oncogene 17:3115-3124 (1998).

Shing DC, Morley-Jacob CA, Roberts I, Nacheva E, Coleman N: Ewing's tumor: novel recurrent chromosomal abnormalities demonstrated by molecular cytogenetic analysis of seven cell lines and one primary culture. Cytogenet Genome Res 97:20-27 (2002).

Singh B, Gogineni SK, Sacks PG, Shaha AR, Shah JP, Stoffel A, Rao PH: Molecular cytogenetic characterization of head and neck squamous cell carcinoma and refinement of $3 \mathrm{q}$ amplification. Cancer Res 61:4506-4513 (2001).

Sirivatanauksorn V, Sirivatanauksorn Y, Gorman PA, Davidson JM, Sheer D, Moore PS, Scarpa A Edwards PA, Lemoine NR: Non-random chromosomal rearrangements in pancreatic cancer cell lines identified by spectral karyotyping. Int J Cancer 91:350-358 (2001)

Sjogren H, Dahlenfors R, Stenman G, Mark J: Observations by G-banding and multicolor spectral karyotyping in a salivary gland basal cell adenoma. Virchows Arch 442:86-87 (2003a).

Sjogren H, Meis-Kindblom JM, Orndal C, Bergh P, Ptaszynski K, Aman P, Kindblom LG, Stenman G: Studies on the molecular pathogenesis of extraskeletal myxoid chondrosarcoma-cytogenetic, molecular genetic, and cDNA microarray analyses. Am J Pathol 162:781-792 (2003b). 
Slater DJ, Hilgenfeld E, Rappaport EF, Shah N, Meek RG, Williams WR, Lovett BD, Osheroff $\mathrm{N}$, et al: $M L L-S E P T I N 6$ fusion recurs in novel translocation of chromosomes $3, \mathrm{X}$, and 11 in infant acute myelomonocytic leukaemia and in $\mathrm{t}(\mathrm{X} ; 11)$ in infant acute myeloid leukaemia, and $M L L$ genomic breakpoint in complex $M L L$ SEPTIN6 rearrangement is a DNA topoisomerase II cleavage site. Oncogene 21:4706-4714 (2002).

Squire JA, Bayani J, Luk C, Unwin L, Tokunaga J, MacMillan C, Irish J, Brown D, et al: Molecular cytogenetic analysis of head and neck squamous cell carcinoma: By comparative genomic hybridization, spectral karyotyping, and expression array analysis. Head Neck 24:874-887 (2002).

Srivastava M, Montagna C, Leighton X, Glasman M, Naga S, Eidelman O, Ried T, Pollard HB: Haploinsufficiency of $A n x 7$ tumor suppressor gene and consequent genomic instability promotes tumorigenesis in the $A n \times 7(+/-)$ mouse. Proc Natl Acad Sci USA 100:14287-14292 (2003).

Stark B, Jeison M, Bar-Am I, Glaser-Gabay L, Mardoukh J, Luria D, Feinmesser M, Goshen Y, et al: Distinct cytogenetic pathways of advancedstage neuroblastoma tumors, detected by spectral karyotyping. Genes Chromosomes Cancer 34:313-324 (2002).

Sy SM, Fan B, Lee TW, Mok TS, Pang E, Yim A, Wong N: Spectral karyotyping indicates complex rearrangements in lung adenocarcinoma of nonsmokers. Cancer Genet Cytogenet 153: 57-59 (2004a).

Sy SM, Wong N, Lee TW, Tse G, Mok TS, Fan B, Pang E, Johnson PJ, Yim A: Distinct patterns of genetic alterations in adenocarcinoma and squamous cell carcinoma of the lung. Eur $\mathrm{J}$ Cancer 40:1082-1094 (2004b).

Tabet AC, Gosset P, Elghezal H, Fontaine S, Martinovic J, Encha Razavi F, Romana S, Vekemans M, Morichon-Delvallez N: Prenatal diagnosis and characterization of an analphoid marker chromosome 16. Prenat Diagn 24:733-736 (2004).

Tanemura M, Suzumori K, Nishikawa N, Ishihara Y: Multicolour spectral karyotyping for complex chromosomal rearrangements in repeated abortion or congenital anomalies. Prenat Diagn 21:1123-1128 (2001).

Tchinda J, Volpert S, Neumann T, Kennerknecht I, Ritter J, Buchner T, Berdel WE, Horst J: Novel $\operatorname{der}(1) t(1 ; 19)$ in two patients with myeloid neoplasias. Cancer Genet Cytogenet 133:61-65 (2002).

Tonon G, Roschke A, Stover K, Shou Y, Kuehl WM, Kirsch IR: Spectral karyotyping combined with locus-specific FISH simultaneously defines genes and chromosomes involved in chromosomal translocations. Genes Chromosomes Cancer 27:418-423 (2000).
Tsao L, Draoua HY, Osunkwo I, Nandula SV, Murty VV, Mansukhani M, Bhagat G, Alobeid B: Mature B-cell acute lymphoblastic leukemia with $\mathrm{t}(9 ; 11)$ translocation: a distinct subset of B-cell acute lymphoblastic leukemia. Mod Pathol 17:832-839 (2004).

van Bokhoven A, Caires A, Maria MD, Schulte AP, Lucia MS, Nordeen SK, Miller GJ, Varella-Garcia M: Spectral karyotype (SKY) analysis of human prostate carcinoma cell lines. Prostate 57: 226-244 (2003).

Vaziri H, Squire JA, Pandita TK, Bradley G, Kuba RM, Zhang H, Gulyas S, Hill RP, et al: Analysis of genomic integrity and p53-dependent G1 checkpoint in telomerase-induced extendedlife-span human fibroblasts. Mol Cell Biol 19: 2373-2379 (1999)

Veldman T, Vignon C, Schrock E, Rowley JD, Ried T: Hidden chromosome abnormalities in haematological malignancies detected by multicolour spectral karyotyping. Nat Genet 15:406410 (1997).

Wang Y, Xue H, Cutz JC, Bayani J, Mawji NR, Chen WG, Goetz LJ, Hayward SW, et al: An orthotopic metastatic prostate cancer model in SCID mice via grafting of a transplantable human prostate tumor line. Lab Invest 85:1392-1404 (2005).

Weaver ZA, McCormack SJ, Liyanage M, du Manoir S, Coleman A, Schrock E, Dickson RB, Ried T: A recurring pattern of chromosomal aberrations in mammary gland tumors of MMTV-cmyc transgenic mice. Genes Chromosomes Cancer 25:251-260 (1999).

Weaver Z, Montagna C, Xu X, Howard T, Gadina M, Brodie SG, Deng CX, Ried T: Mammary tumors in mice conditionally mutant for Brcal exhibit gross genomic instability and centrosome amplification yet display a recurring distribution of genomic imbalances that is similar to human breast cancer. Oncogene 21:50975107 (2002).

Weimer J, Koehler MR, Wiedemann U, Attermeyer P, Jacobsen A, Karow D, Kiechl M, Jonat W, Arnold N: Highly comprehensive karyotype analysis by a combination of spectral karyotyping (SKY), microdissection, and reverse painting (SKY-MD). Chromosome Res 9:395-402 (2001).

Wiener F, Kuschak TI, Ohno S, Mai S: Deregulated expression of c-Myc in a translocation-negative plasmacytoma on extrachromosomal elements that carry IgH and myc genes. Proc Natl Acad Sci USA 96:13967-13972 (1999).

Wong KF, So CC, Wong N, Siu LL, Kwong YL, Chan JK: Sinonasal angiosarcoma with marrow involvement at presentation mimicking malignant lymphoma: cytogenetic analysis using multiple techniques. Cancer Genet Cytogenet 129:64-68 (2001).

Wong N, Lai P, Pang E, Leung TW, Lau JW, Johnson PJ: A comprehensive karyotypic study on human hepatocellular carcinoma by spectral karyotyping. Hepatology 32:1060-1068 (2000).
Wong N, Hui AB, Fan B, Lo KW, Pang E, Leung SF, Huang DP, Johnson PJ: Molecular cytogenetic characterization of nasopharyngeal carcinoma cell lines and xenografts by comparative genomic hybridization and spectral karyotyping. Cancer Genet Cytogenet 140:124-132 (2003).

Wong QW, Wong N, Lai PB, To KF, Wong N: Clonal relationship of tumor nodules in hepatocellular carcinoma: a hierarchical clustering analysis of comparative genomic hybridization data. Hum Pathol 36:893-898 (2005).

$\mathrm{Xu} \mathrm{J}$, Chen Z: Advances in molecular cytogenetics for the evaluation of mental retardation. Am J Med Genet C Semin Med Genet 117:15-24 (2003).

Yamashita Y, Nishida K, Okuda T, Nomura K, Matsumoto Y, Mitsufuji S, Horiike S, Hata H, Sakakura C, Hagiwara A, Yamagishi H, Taniwaki M: Recurrent chromosomal rearrangements at bands $8 \mathrm{q} 24$ and 11q13 in gastric cancer as detected by multicolor spectral karyotyping. World J Gastroenterol 11:5129-5135 (2005).

Yaron Y, Carmon E, Goldstein M, Voskoboinik N, Ochshorn Y, Gelman-Kohan Z, Orr-Urtreger A: The clinical application of spectral karyotyping (SKY) in the analysis of prenatally diagnosed extra structurally abnormal chromosomes (ESACs). Prenat Diagn 23:74-79 (2003).

Ye CJ, Lu W, Liu G, Bremer SW, Wang YA, Moens P, Hughes M, Krawetz SA, Heng HH: The combination of SKY and specific loci detection with FISH or immunostaining. Cytogenet Cell Genet 93:195-202 (2001).

Zhang FF, Murata-Collins JL, Gaytan P, Forman SJ, Kopecky KJ, Willman CL, Appelbaum FR, Slovak ML: Twenty-four-color spectral karyotyping reveals chromosome aberrations in cytogenetically normal acute myeloid leukemia Genes Chromosomes Cancer 28:318-328 (2000).

Zielenska M, Zhang ZM, Ng K, Marrano P, Bayani J, Ramirez OC, Sorensen P, Thorner P, et al: Acquisition of secondary structural chromosomal changes in pediatric Ewing sarcoma is a probable prognostic factor for tumor response and clinical outcome. Cancer 91:2156-2164 (2001).

Zimonjic DB, Pollock JL, Westervelt P, Popescu NC, Ley TJ: Acquired, nonrandom chromosomal abnormalities associated with the development of acute promyelocytic leukemia in transgenic mice. Proc Natl Acad Sci USA 97:13306-13311 (2000).

Zimonjic DB, Keck-Waggoner C, Popescu NC: Novel genomic imbalances and chromosome translocations involving c-myc gene in Burkitt's lymphoma. Leukemia 15:1582-1588 (2001).

Zitzelsberger H, Bruch J, Smida J, Hieber L, Peddie CM, Bryant PE, Riches AC, Fung J, et al: Clonal chromosomal aberrations in simian virus 40 transfected human thyroid cells and in derived tumors developed after in vitro irradiation. Int J Cancer 96:166-177 (2001). 